\title{
Lipids and Oxidative Stress Associated with Ethanol-Induced Neurological Damage
}

\author{
José A. Hernández, ${ }^{1}$ Rosa C. López-Sánchez, ${ }^{1}$ and Adela Rendón-Ramírez ${ }^{2}$ \\ ${ }^{1}$ Tecnologico de Monterrey, Escuela Nacional de Medicina, 64710 Monterrey, NL, Mexico \\ ${ }^{2}$ Unidad de Biofísica (CSIC, UPV/EHU) and Departamento de Bioquímica, Universidad del País Vasco, Apartado 644, \\ 48080 Bilbao, Spain \\ Correspondence should be addressed to Adela Rendón-Ramírez; aderendon@gmail.com
}

Received 26 September 2015; Revised 10 December 2015; Accepted 13 December 2015

Academic Editor: Tanea T. Reed

Copyright (C) 2016 José A. Hernández et al. This is an open access article distributed under the Creative Commons Attribution License, which permits unrestricted use, distribution, and reproduction in any medium, provided the original work is properly cited.

\begin{abstract}
The excessive intake of alcohol is a serious public health problem, especially given the severe damage provoked by chronic or prenatal exposure to alcohol that affects many physiological processes, such as memory, motor function, and cognitive abilities. This damage is related to the ethanol oxidation in the brain. The metabolism of ethanol to acetaldehyde and then to acetate is associated with the production of reactive oxygen species that accentuate the oxidative state of cells. This metabolism of ethanol can induce the oxidation of the fatty acids in phospholipids, and the bioactive aldehydes produced are known to be associated with neurotoxicity and neurodegeneration. As such, here we will review the role of lipids in the neuronal damage induced by ethanol-related oxidative stress and the role that lipids play in the related compensatory or defense mechanisms.
\end{abstract}

\section{Introduction}

A clear relationship has been established between ethanol intake, addiction and dependency [1-3], and several risk factors for chronic disease and injury [4]. Indeed, the public health problem associated with increased alcohol consumption and alcoholism [5,6] is becoming ever more severe due to the increased economic burden of the complications on the health national systems and the cost of the relevant treatments [4, 7-10]. Alcoholism provokes high rates of mortality and it increases in risk of several disabling disorders $[4,11]$. Such damage can be classified in function of the organs involved (liver, kidney, heart, brain, etc.), the type of intake (acute or chronic), or the subject's age at the time of exposure to ethanol (prenatal, neonatal, or adult). In summary, ethanol has several negative health effects, especially if we consider prenatal exposure where the brain is a major target for the damage provoked.

\section{Effects of Ethanol in the Brain}

Ethanol has many effects in the brain depending on the age of exposure (prenatal, postnatal, or adult). For example, aggressive behavior and depression are observed after acute postnatal exposure to ethanol, possibly due to a decrease in circulating tryptophan, followed by the depletion of serotonin in the brain [12, 13]. Another effect of acute postnatal alcohol exposure is related to impaired impulsive and control behavior [14, 15], although few in vivo studies have focused on this issue. Cognitive performance has been associated with specific prefrontal cortical regions in Rhesus Macaque monkeys [11] and GABA receptors in this structure have been implicated in the effects of acute postnatal ethanol exposure [16-18]. Indeed, GABA was found to be a mediator in ethanol-induced ataxia $[18,19]$.

The most severe alcohol-related damage is found following acute prenatal or chronic pre- and postnatal ethanol exposure, effects that have been associated with a loss of neurons (Table 1). In terms of prenatal exposure, the babies born to women that drink alcohol excessively during pregnancy may suffer from fetal alcohol syndrome [20], a condition characterized by specific craniofacial abnormalities, pre- and postnatal growth deficiencies, and nervous system dysfunction that is manifested as persistent intellectual, behavioral, and neurological defects $[5,21]$. These latter symptoms have 


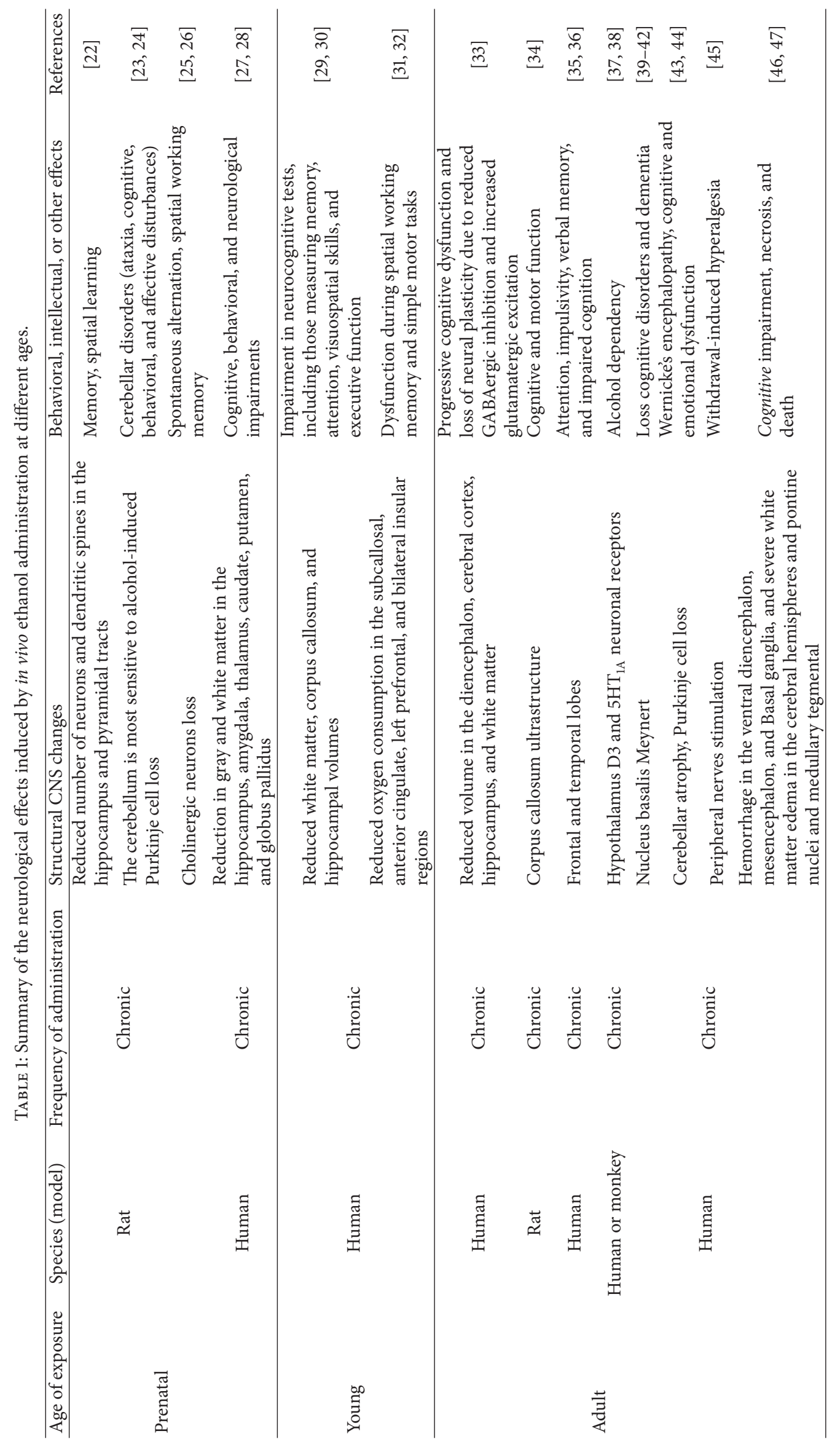


been related to neurodegeneration in experimental animal models (see Table 1 for a summary of some of the available literature).

Chronic alcohol exposure has been associated with permanent neuronal loss in brain regions like the hippocampus and cerebellum. Moreover, in vivo studies have demonstrated neurological effects following chronic ethanol exposure in young and adult populations, with deterioration in memory, motor function, cognition, and so forth. All these effects could be due to neurotoxicity or neurodegeneration, and there is evidence that oxidative stress associated with ethanol metabolism is involved.

\section{The Pharmacokinetics of Ethanol}

The ethanol concentration that can be found in blood following its ingestion depends on its pharmacokinetics (PK). PK determines not only the time-course and persistence of ethanol in blood but also the amount of alcohol and its metabolic products that accumulate in different tissues, and hence their pharmacological and toxicological responses [48].

3.1. Absorption. In adults, the ethanol ingested is almost completely and instantly absorbed by passive diffusion, reaching a peak concentration in humans between 30 and $90 \mathrm{~min}$. Absorption is more efficient in the small intestine than in stomach [49], a difference in absorption that is due to two factors. First, the thickness of mucus that protects the stomach appears to have a resistance $\sim 16$ times greater than that which protects the small intestine $[49,50]$, which also has a greater intestinal absorption surface due to the presence villi and microvilli [51]. The second difference reflects the speed of stirring caused by peristalsis, which is more important in the small intestine than in the stomach, playing a role in gastric emptying and in the intestinal transit time [49].

In addition, the presence of food is another factor that modifies the absorption rate [52], mainly as food reduces gastric emptying and ethanol is absorbed more slowly [53]. Solid food intake can reduce the ethanol absorption rate by $30 \%$ and it has been suggested that this effect is due to the need for food digestion prior to absorption process. As such, if food is taken in as a liquid then it would not produce this effect $[49,54]$. Moreover, a small amount of ethanol can be oxidized to acetaldehyde by alcohol dehydrogenase $(\mathrm{ADH})$ classes I and IV $[52,55]$ in the stomach and intestine. This acetaldehyde can be absorbed along with ethanol and metabolized by the liver or other tissues.

\subsection{First Pass Metabolism and the Distribution of Ethanol.} The amount of alcohol in any given tissue depends on its relative concentration in the blood, which is a function of first pass metabolism [49], that is, the oxidation of ethanol in the stomach, intestine, and liver.

Most first pass metabolism occurs in the liver $[49,55]$ and the rate-limiting step is the oxidation of ethanol to acetaldehyde. This reaction is catalyzed by proteins of the ADH family [56], of which class I (ADH1) and III (ADH3) enzymes metabolize ethanol in the liver $[57,58]$. These two types of enzymes differ in their $\mathrm{Km}$, with ADH1 having a low $\mathrm{Km}$ while $\mathrm{ADH} 3$ has a high $\mathrm{Km}$ value $[57,59]$. Consequently $\mathrm{ADH} 3$ plays a more important role in the metabolism of alcohol at high concentrations. In addition, microsomal ethanol oxidizing system (MEOS) and catalase contribute to the metabolism of alcohol in specific circumstances, such as high ethanol concentrations $[48,60]$.

The acetaldehyde produced by the oxidation of ethanol is thereafter transformed to acetate by aldehyde dehydrogenase (ALDH) [61], which can be further metabolized through the tricarboxylic acid cycle to generate energy, or these metabolites can be deposited in the plasma [62, 63]. Indeed, increases in acetate but not acetaldehyde can be detected in human plasma after ethanol intake $[64,65]$ (Figure 1).

The efficiency of ethanol metabolism is dependent on the enzymatic activity and pathways involved. It has been reported that $\mathrm{ADH}$, cytochrome P450 (CYP), and ALDH show genetic variations (ADH1B, ALDH2, CYP2E1* 6 , and CYP2E1* $7 \mathrm{~B}$ besides others) that affect enzymatic activity in the liver and alcohol metabolism [66-68]. As a result, ethanol's pharmacokinetic and pharmacodynamic properties are affected by this genetic variation, as reflected in interracial and ethnic pharmacological differences [56, 66-71]. Consequently the risk of developing diseases may increase in certain populations, including that of hypertension [70], alcohol dependence, and several types of alcohol-related cancer $[60$, 72-75].

After first pass metabolism, the remaining ethanol and its metabolites are distributed in different tissue, and the excess alcohol is excreted in the breath, urine, and sweat [56]. The distribution of ethanol throughout the body is driven in direct proportion to water content of each tissue, especially at the ethanol steady-state. Since ethanol is a small, polar molecule, the distribution volume of ethanol is dependent on the total body water of an individual (50 to $60 \%$ lean body weight) [76-78]. The variation in the distribution volume of ethanol has been evaluated for women and men, and in both sexes, the distribution volume decreases as the body mass index increases [79].

Alcohol-driven physiological changes, such as vascular effects (vasodilation) or changes in cardiac output, can also modify tissue blood flow and ethanol distribution [78]. Since the blood flow to the brain remains relatively constant, changes in the blood concentration of ethanol are the most relevant factor influencing the amount of ethanol delivered to the brain and therefore for the different levels of brain intoxication [78-80].

The distribution of ethanol is also particularly relevant during pregnancy, as 1-2 hours after maternal alcohol ingestion the fetal alcohol concentrations reach levels that are nearly equivalent to the maternal levels [81]. The elimination of ethanol by the fetus is impaired due to its reduced metabolic capacity. Thus, fetal exposure is prolonged through the reuptake of amniotic-fluid containing ethanol [81]. Ultimately, the elimination of alcohol from the fetus relies on the mother's metabolic capacity, which inevitably is a process that occurs late, meaning that the fetus is exposed to the toxicological effects of alcohol [82]. Therefore, many of the physical effects of ethanol on brain structure not only 


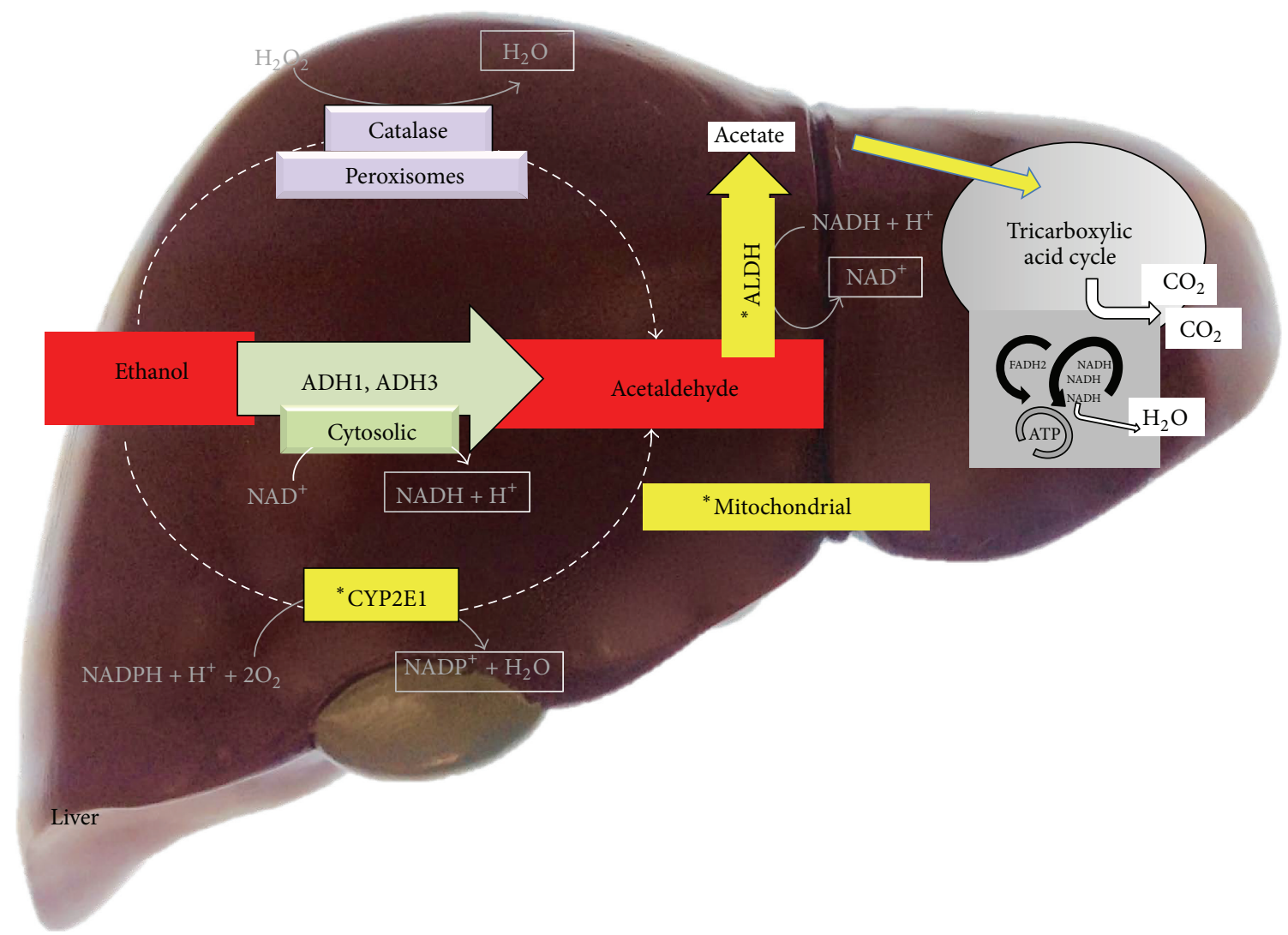

FIGURE 1: Mechanisms of ethanol metabolism in the liver. Alcohol dehydrogenase (ADH) and aldehyde dehydrogenase (ALDH) are the main enzymes that convert ethanol to acetate in the liver.

affect neurobehavioral features during fetal development but may also persist into childhood, potentially enduring until adulthood [82, 83].

3.3. Ethanol and Acetate Can Reach the Brain. Ethanol can cross the blood-brain barrier and it can be metabolized in the brain. Indeed, ethanol has been found in the human brain after alcohol intake [84], although metabolites of ethanol, like acetate, can also reach the brain as products of first pass metabolism [85]. Recently, the metabolism of [2-(13)C]ethanol was evaluated in the brains of rats, and products such as labeled acetate, glutamate, glutamine, and GABA were detected found [86].

\section{Metabolism of Ethanol and Acetate in the Brain}

The oxidation of ethanol to acetaldehyde can occur in the brain through pathways that involve catalase, cytochrome CYP2E1, and ADH. The main pathway to metabolize ethanol in the liver is that involving $\mathrm{ADH}$, although it has not been definitively shown to play a role in ethanol metabolism in the brain. In certain regions of the adult rat, mouse, and human brain it has been possible to identify $\mathrm{ADH}$ mRNA transcripts, with $\mathrm{ADH} 1$ and $\mathrm{ADH} 4$ expressed at distinct sites $[87,88]$, yet with no detectable activity after exposure to ethanol. Nonetheless, ADH4 inhibition avoids the synaptic dysfunction associated with severe alcohol intoxication in the hippocampus [89]. Moreover ADH activity (ADH1, ADH3, and $\mathrm{ADH} 4$ ) was found in the human brain but under pathological process like brain cancer [73] and Alzheimer's disease [90], and not induced by alcohol intake. In addition, and despite fulfilling a less prominent role in ethanol metabolism $[85,91], \mathrm{ADH}$ s have been related to enhanced voluntary alcohol intake in rats [92].

Other pathways metabolize ethanol in the brain. Catalase and CYP2E1 are the main pathways; there is evidence that they do indeed play an important role in ethanol oxidation to acetaldehyde in the brain [91]. Indeed, acetaldehyde production in the brain in vivo depends on catalase activity [85, 93] and catalase appears to be expressed in all neural cells. Peroxisomal catalase is a tetrameric, heme-containing enzyme that, in addition to converting hydrogen peroxide $\left(\mathrm{H}_{2} \mathrm{O}_{2}\right)$ to water and oxygen, can also oxidize ethanol to acetaldehyde. The discovery of the catalase pathway for acetaldehyde formation in the brain represented an important first step in our understanding of the role of acetaldehyde in the effects of ethanol in the brain [94]. Studies using inhibitors of catalase and acatalasemic mice revealed that catalase is responsible for approximately half of the ethanol metabolism occurring in the CNS [91]. Indeed, inhibitors of catalase are also effective in inhibiting the production of acetaldehyde.

The cytochrome P450 enzymes (CYP2E1) that are involved in ethanol metabolism in the liver have also been implicated in its metabolism in the brain. CYP2E1 reduces 
molecular oxygen to water and thus ethanol is oxidized to acetaldehyde. This enzyme is induced in response to chronic drinking and it may contribute to the increased rates of ethanol elimination in heavy drinkers. Some endogenous substrates for CYP2E1 include acetone and fatty acids, both of which are abundant in the brain [95]. The CYP2E1 system fulfills an important role in the generation of reactive oxygen species (ROS) and exposure to ethanol is related to the accumulation of ROS, which in rat brain homogenates may be attributed to the induction of CYP2E1 [96]. Not only ethanol but many other substrates are also metabolized by CYP2E1, including neurotoxins or procarcinogens, producing reactive intermediates [97, 98]. Moreover, in human neurons CYP2E1 is known to generate ROS and nitric oxide through the induction of NADPH/xanthine oxidase and nitric oxide synthase [99].

Therefore, CYP2E1 and catalase are the main pathways in the brain that metabolize ethanol to acetaldehyde, while $\mathrm{ADH}$ appears to play a minor role. Acetaldehyde is a biologically active compound and it has been implicated in alcohol addiction [100, 101], as well as inducing euphoria at low concentrations [102]. The effects of ethanol are modulated by acetaldehyde $[100,103]$, which in turn may react with endogenous substances to form other biologically active compounds. Acetaldehydes along with other proteins (adducts) were found in mice brain after alcohol consumption and in alcoholic human brains, suggesting they are involved in neural damage [104, 105]. Moreover adducts like salsolinol (formed when acetaldehyde binds to dopamine) were also seen to be involved in neurotoxicity [106] and in reinforcing addictive ethanol conduct [107]. Salsolinol has been identified in the brain and cerebrospinal fluid of patients with Parkinson disease, and it has been proposed to increase ROS production along with a reduction of glutathione [108], as well as reducing intracellular ATP and thereby acting as an inhibitor of mitochondrial energy supply. Thus, acetaldehyde reinforces its own effects or enhances the addictive action of ethanol $[109,110]$.

As a result, acetaldehyde oxidation is required for detoxification and it can be metabolized to acetate by ALDH [111]. ALDH is critically important and the risk of alcoholinduced toxicity in individuals with mutant ALDH2 increases remarkably [112], while ALDH2 overexpression diminishes alcohol-related ROS production [113]. However, the accumulation of NADH increases in association with ALDH activity [114] and if the $\mathrm{NAD}^{+} / \mathrm{NADH}$ ratio decreases, the amounts of superoxide radicals increase $[115,116]$. Moreover, although ALDH activity has beneficial effects, such as in the reduction of acetaldehyde, it also produces free radicals. Finally, the acetate produced by ALDH is metabolized in the Krebs cycle to produce energy or provide intermediaries for other molecules. Recent research showed that oxidation of [13]C-acetate generates specific neurotransmitters, as [13]C-glutamine, glutamate, and GABA levels were higher in chronic ethanol-exposed rats than in controls [86]. The production of these molecules may be related to the known effects of GABA receptors [16, 17, 19, 117], although other receptors are also involved in the effects of ethanol, such as dopamine, acetylcholine, and NMDA receptors [118-120] (Figure 2).

\section{Oxidative Stress Produced by Ethanol}

ROS are produced by exposure to ethanol [85] and they are associated with the effects of ethanol in the brain $[92,99,101$, 121-125], where ROS-related damage is due to oxidative stress $[99,124,126-128]$. The oxidative balance is a result of the amount of ROS that accumulates and the activity of antioxidant enzymes. In the brain, antioxidant enzymes are present in the cortex, cerebellum, hypothalamus, striatum, and spinal cord, and they include glutathione peroxidase, superoxide dismutase, glutathione reductase, and peroxiredoxin [129]. When the oxidative balance is disturbed, oxidative stress develops that affects the cell as a whole, as well as proteins, lipids, and DNA individually, provoking neurotoxicity or neurodegeneration.

\section{The Antioxidant System and the Effects of Ethanol}

The formation of ROS accompanies many physiological processes, such that the body has developed a system of antioxidant protection against their harmful effects. In the brain, where the generation of free radicals is particularly severe, it is essential that the antioxidant system functions correctly [130]. Antioxidant activity is considered as enzymatic or nonenzymatic based on the mechanism of action involved.

6.1. Superoxide Dismutase (SOD). It is an enzyme that catalyzes the dismutation of the superoxide anion to hydrogen peroxide, which is then decomposed by catalases primarily located in the peroxisomes. There are two main SOD isoenzymes found in the CNS of mammals: Mn-SOD (dependent on mitochondrial manganese ions) and $\mathrm{Cu}, \mathrm{Zn}$ SOD (SOD-1) present in the cytoplasm, microsomes, and synaptosomes [131]. Increased SOD activity is considered to be an adaptive response to oxidative stress, such as that induced by acute ethanol toxicity in the cerebral cortex [132]. However, acute ethanol intoxication reduces the activity of $\mathrm{Cu}, \mathrm{Zn}-\mathrm{SOD}$ in the cytosolic and microsomal fraction of the rat brain, and Mn-SOD activity in the mitochondria [131]. SOD interacts closely with catalase, which catalyzes the deprotonation of peroxide hydrogen and the oxidation of substances like methanol, ethanol, formate, nitrite, and quinones.

6.2. Catalase. In mammals, catalase is primarily located in the liver, erythrocytes, kidneys, and CNS. In the CNS, it can be found in microsomes [133] and it has been shown that, in acute ethanol poisoning, there is an increase of catalase activity in the cytosol, microsomes, and synaptosomes, as well as a reduction in the mitochondria of the rat CNS [131]. The increase in catalase activity following ethanol intake and its effects in the CNS are associated with weak ADH activity. This increase in catalase activity in the CNS may be adaptive processes induced by the increase in the hydrogen peroxide 


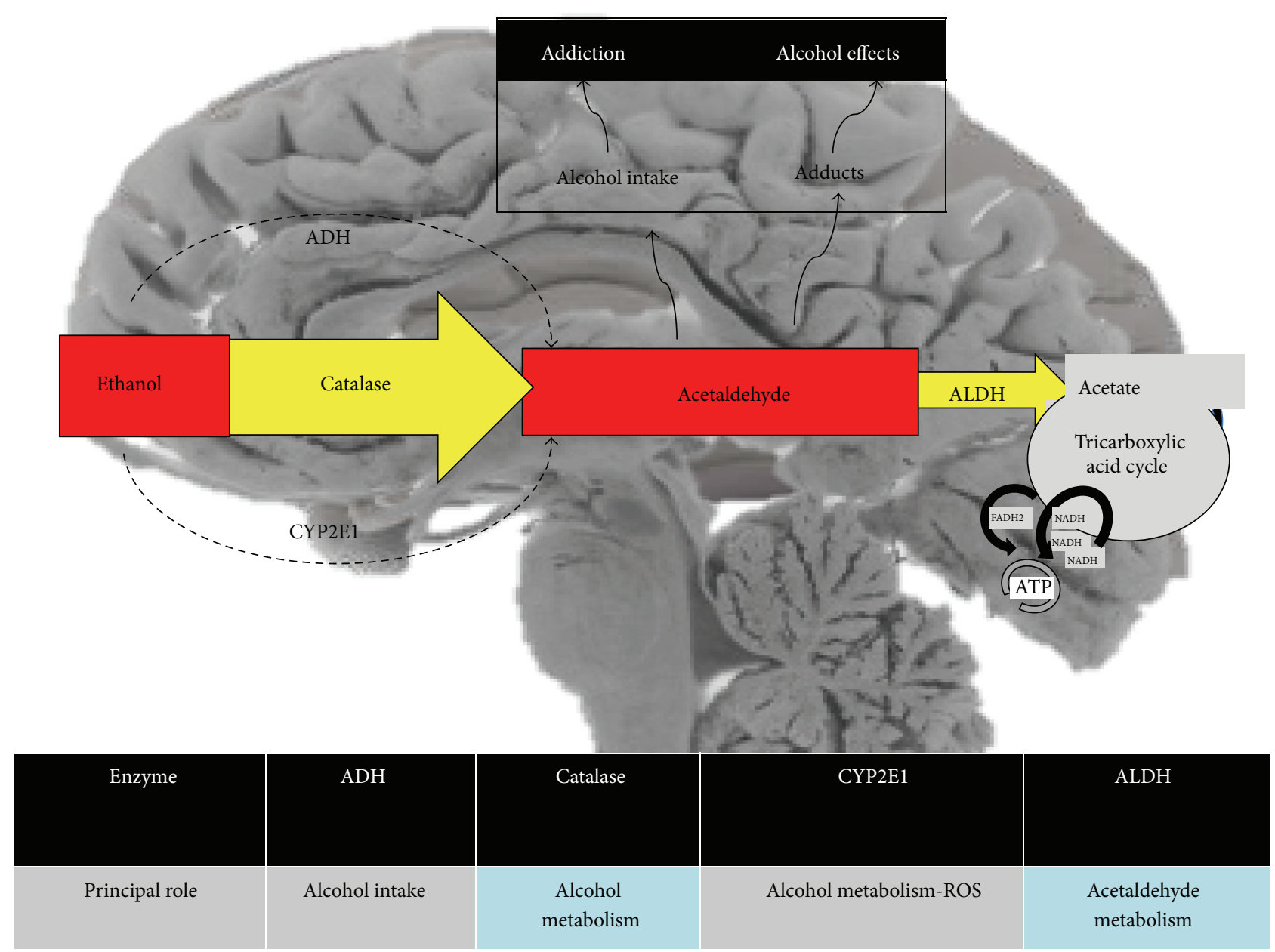

Figure 2: Enzymes related to ethanol metabolism in the brain and their principal role. Note the importance of acetaldehyde in ethanol metabolism.

generated, as what occurs in the CNS of animals exposed to high concentrations of ethanol [134].

6.3. Glutathione Peroxidase (GSH-Px). It is present in many tissues, as well as in the neurons and glia of the CNS $[135,136]$. The role of GSH-Px is limited to the reduction of peroxides in which glutathione participates, which is accompanied by the formation of glutathione disulfide. In the rat and human CNS, the greatest glutathione peroxidase activity is observed in the gray and white matter of the cerebral cortex $[137,138]$.

6.4. Glutathione Reductase (GRed). It is an enzyme present in the cytosol and in the mitochondria of most cells, catalyzing the regeneration of reduced glutathione oxidation at the expense of NADPH. Most GRed activity is found in neurons and glial cells [139], and acute ethanol poisoning significantly dampens GRed activity in the cerebral cortex [140].

The activity of antioxidant enzymes is significantly altered in the CNS of animals chronically intoxicated with ethanol. The antioxidative capacity of the CNS also depends on exogenous antioxidants obtained by the organism through its dietary intake. The most important exogenous antioxidant in the CNS is vitamin $\mathrm{E}$, and both vitamin $\mathrm{E}$ and vitamin $\mathrm{C}$ content in the CNS falls after ethanol consumption, whereas vitamin A content increases [131].

\section{Oxidized Fatty Acids as a Consequence of Oxidative Stress}

Lipid peroxidation affects polyunsaturated fatty acids in membrane phospholipids as oxidative stress increases, producing bioactive aldehydes like 4-hydroxyalkenals and malondialdehyde [141]. Oxidative stress and the products of lipid peroxidation, 4-hydroxynonenal (HNE) [99, 142-145] or malondialdehyde [141, 146, 147], have been related to decreased neuronal viability in some studies. Ethanolinduced lipoperoxidation by oxidative stress [142] and its products decrease the intracellular reduced glutathione and increase its oxidized form [148]. HNE has also been associated with increases in mitochondrial permeability and cytochrome c release $[143,149,150]$, the latter triggering apoptotic cell death by activating caspases [145, 150]. Interestingly, the toxicity mediated by the product of lipoperoxidation was weaker when glutathione transferase A4-4 activity 


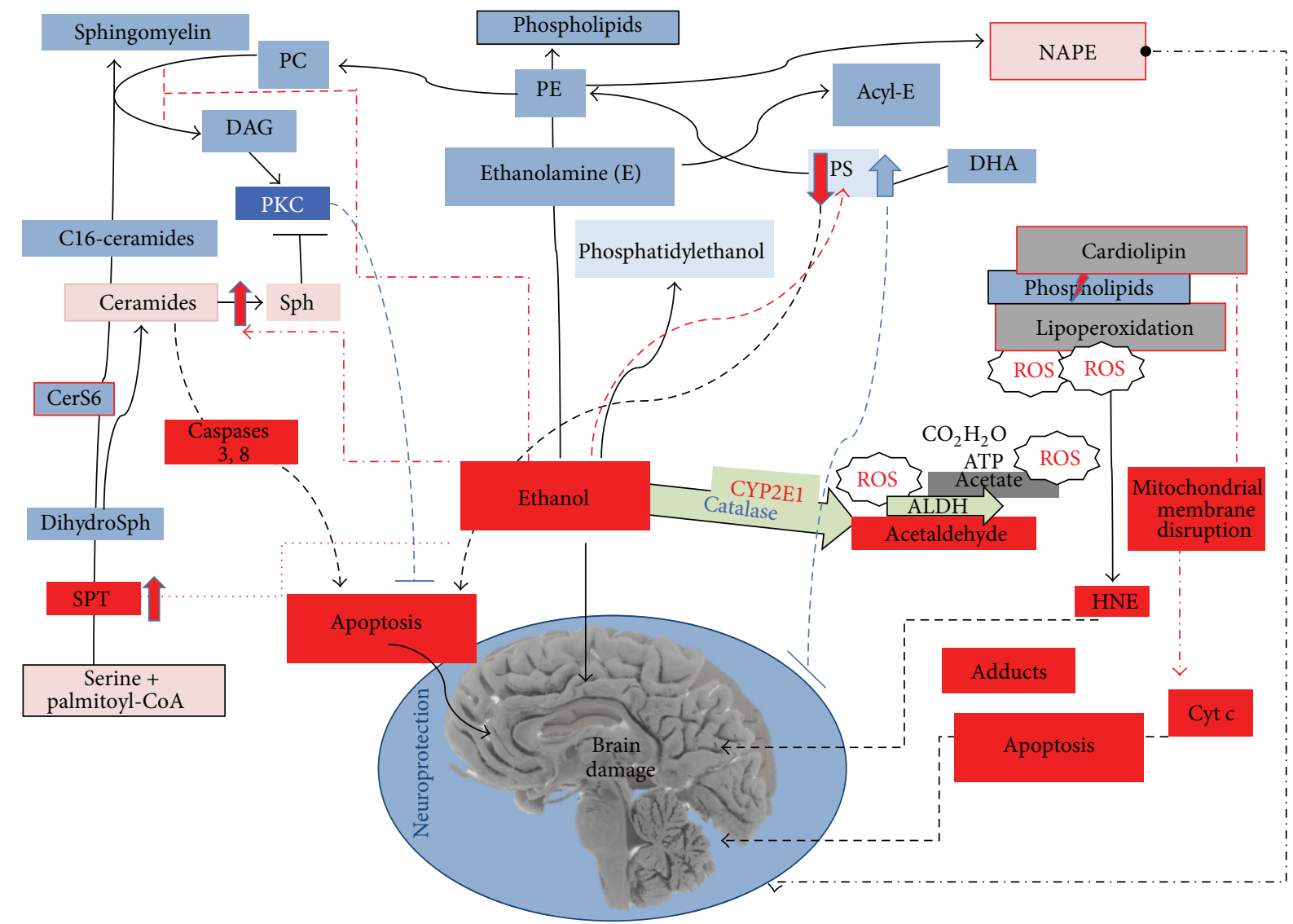

FIGURE 3: The role of lipids in ethanol-induced damage. Lipid metabolic pathways may be involved in neurodegeneration, such as lipoperoxidation, reduced phosphatidylserine (PS), N-acyl-PE (NAPE), and ceramide/Sph (sphingosine). Some lipids are produced as a compensatory mechanism and they fulfill a protective role, such as c16-ceramide, PS, sphingomyelin (SM), phosphatidyl ethanolamine (PE), and phosphatidylethanol.

was enhanced and glutathionyl-HNE was produced, avoiding the accumulation of HNE [150,151] and possibly serving as a mechanism of tolerance. However, the activation of glutathione transferase A4-4 was suppressed in the presence of anionic phospholipids like cardiolipin [152]. Furthermore, the ability of HNE to produce glutathionyl-HNE was prevented by a PLA2 inhibitor [153], suggesting a role of PLA2 in the production of HNE.

\section{The Role of Phospholipids in Stress Damage}

Cardiolipin is a phospholipid and it is the major component of mitochondrial membranes, although ethanolinduced oxidative stress provokes a loss of this lipid $[152,154-$ $157]$ in conjunction with the appearance of HNE $[157,158]$. Therefore, cardiolipin oxidation occurs following ethanol ingestion and consequently its fatty acids are released from phospholipids by PLA2. When cardiolipin is affected by ethanol, mitochondrial function is impaired and the outer mitochondrial membrane may disintegrate $[157,159]$, which could induce the release of cytochrome $\mathrm{c}$ from the mitochondria and trigger an apoptotic cascade mediated by caspases $[158,160]$. Interestingly, the neurodegeneration induced by ethanol can be prevented by an inhibitor of PLA2 in vitro $[153,161]$.
Phosphatidylserine (PS) has also been shown to play a role in apoptotic signaling, and both the reduction in PS and the enhanced neuronal cell death that ensues during the developmental period may contribute to the brain defects often observed in fetal alcohol syndrome [162]. Meanwhile, docosahexaenoic acid (DHA: 22:6n-3) prevents neuronal apoptosis by promoting PS accumulation [162], while conversely, PLA2 activity and oxidation-mediated HNE production may diminish the levels of PS.

\section{Ceramide Related to Neurodegeneration}

Ceramides are produced in the central nervous system by de novo synthesis or sphingomyelin hydrolysis [163]. Ceramide has been shown to accumulate in mitochondria upon the induction of apoptotic processes related to neurodegeneration [164-175]. The expression of serine palmitoyltransferase was localized in neurons and it was enhanced in caspase 3-positive neurons induced by ethanol [172], indicating that de novo ceramide synthesis participates in ethanolinduced apoptotic neurodegeneration in the brain. Although ceramide synthase 6 (CerS6) fulfills a protective role, this enzyme produces $\mathrm{C} 16$-ceramides and they are the precursors of other sphingolipids, such as sphingomyelin and glucosylceramide. Interestingly, CerS6 is enhanced within hours 


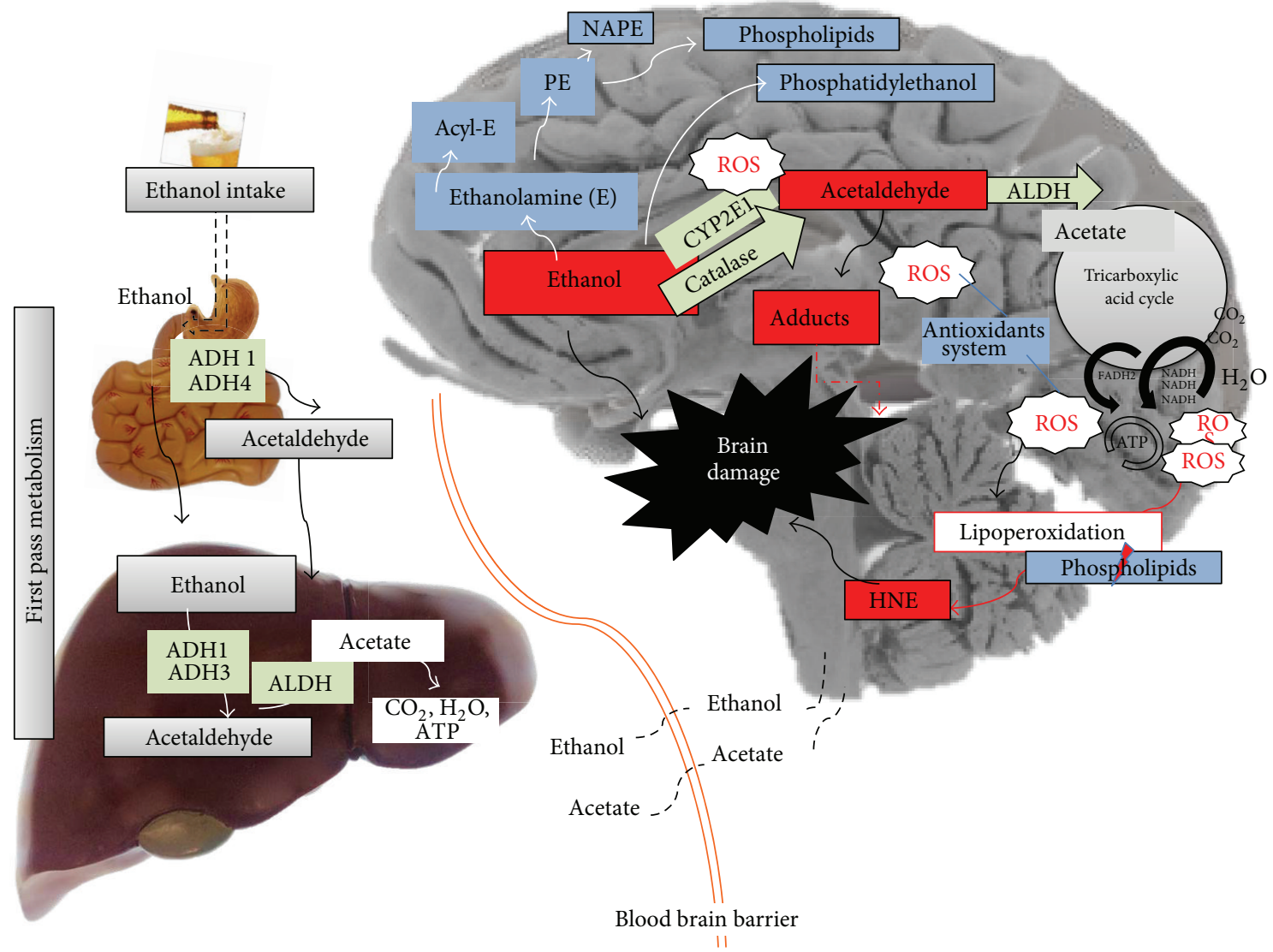

FIGURE 4: Oxidative stress and the role of lipids related to ethanol metabolism in the brain. Ethanol intake undergoes first pass metabolism in the stomach, intestine, and liver, although excess ethanol reaches the brain. Ethanol metabolism increases oxidative stress and lipid oxidation occurs, affecting mitochondrial membrane phospholipids and provoking cell death, thereby provoking damage in the brain. However ethanol-induced damage can be avoided by the activation of compensatory mechanisms involving lipids: $\mathrm{E}$ (ethanolamine), PE (phosphatidylethanolamine), acyl-E (acyl-ethanolamine), and NAPE (N-acyl-phosphatidylethanolamine).

of ethanol withdrawal as a compensatory effect [176]. In summary, ceramide is an apoptotic signal [173] but it is also necessary for the sphingomyelin synthesis required to produce diacylglycerol (DAG), which in turn activates PKC [177], thereby avoiding apoptosis [178].

\section{Lipids Potentially Involved in the Compensatory Mechanisms Protecting against Ethanol-Induced Damage}

While some lipids are altered to signal cells for destruction, others seem to offset some of the effects that occur due to oxidation. For example, there is more cholesterol in neuron membranes exposed to ethanol [155]. Cholesterol is known to provide rigidity to membranes and ethanol is effective in disrupting unstable lipid membranes. Hence, an increase in the cholesterol present in membranes may represent a compensatory mechanism to combat ethanol damage. Indeed, when mitochondrial cardiolipin is oxidized and its fatty acid released, membranes become unstable due to a loss of rigidity.

Other lipids can also reduce the availability or the effects of metabolites of ethanol, such as phosphatidylethanolamine, phosphatidylethanol, and acylethanolamine. Ethanol exposure augments the amount of phosphatidylethanolamine due to the attachment of aminated ethanol to citidyldiphosphate $[152,179]$, resulting in the production of phosphatidylethanolamine through the Kennedy pathway [180]. Moreover, phosphatidylethanolamine can serve as a substrate for acyltransferases and indeed $\mathrm{N}$-acylphosphoethanolamine (NAPE) is produced following ethanol exposure [168]. The amount of NAPE in membranes augments under cellular stress and as a result of tissue damage [181-184], and NAPE represents a precursor of the $\mathrm{N}$-acylethanolamines [185] involved in learning and memory [186], neuroinflammation [187], oxidative stress, neuroprotection, and neurogenesis. Palmitoylethanolamine treatment of cultured cells produces neuroprotection against oxidative stress, impeding apoptosis [187-189] and protection in mice with chronic constriction injury [190]. Moreover, the endocannabinoid anandamide is also involved in neurodegeneration and thus acylethanolamines, and especially palmitoylethanolamine, appear to play an important role as neuroprotectors. Acylethanolamines can be found in the mitochondria in vitro [191] and palmitoyl requires carnitine to enter mitochondria. When cells or animals receive carnitine it acts as a neuroprotective agent, preventing ethanol-induced damage [147]. Furthermore, $₫$ type- 3 unsaturated fatty acids and DHA provide neuroprotection in conjunction with an increase in 
the formation of acylethanolamine $[161,162]$, suggesting that the formation of the latter prevents the damage caused by the oxidative metabolism of ethanol. Finally, ethanol can also be metabolized as phosphatidylethanol, a molecule found in the brain of rats [192] that is possibly formed to avoid ethanol oxidation.

\section{Conclusions}

Lipid metabolism is clearly affected by exposure to ethanol (Figure 3), and the alterations to lipid components like cardiolipin and some phospholipids in response to ethanol provide evidence of cell damage. The formation of oxidized species, abnormal lipids, and dysfunctional membranes due to ethanol uptake also provokes cell degeneration. However, compensatory mechanisms exist to dampen the effects of these metabolic events and to minimize cell damage, as reflected by the neuroprotective activities of natural lipids like DHA, esters, vitamin E, and so forth. Thus, ethanolinduced neurodegeneration is at least partly the result of the equilibrium maintained between the toxicity of signaling lipids and the protection they confer on the cell (Figure 4).

\section{Conflict of Interests}

The authors have no conflict of interests to declare.

\section{Acknowledgment}

The authors are grateful to Dr. Mark Sefton for his revisions and comments on the final version of the paper.

\section{References}

[1] K. G. Chartier, M. N. Hesselbrock, and V. M. Hesselbrock, "Ethnicity and gender comparisons of health consequences in adults with alcohol dependence," Substance Use and Misuse, vol. 48, no. 3, pp. 200-210, 2013.

[2] K. J. Kiecolt, S. H. Aggen, and K. S. Kendler, "Genetic and environmental influences on the relationship between mastery and alcohol dependence," Alcoholism: Clinical and Experimental Research, vol. 37, no. 6, pp. 905-913, 2013.

[3] S. Alaux-Cantin, V. Warnault, R. Legastelois et al., "Alcohol intoxications during adolescence increase motivation for alcohol in adult rats and induce neuroadaptations in the nucleus accumbens," Neuropharmacology, vol. 67, pp. 521-531, 2013.

[4] M. Roerecke and J. Rehm, "Cause-specific mortality risk in alcohol use disorder treatment patients: a systematic review and meta-analysis," International Journal of Epidemiology, vol. 43, no. 3, Article ID dyu018, pp. 906-919, 2014.

[5] F. Calhoun, M. L. Attilia, P. A. Spagnolo, C. Rotondo, R. Mancinelli, and M. Ceccanti, "National Institute on Alcohol Abuse and Alcoholism and the study of fetal alcohol spectrum disorders. The International Consortium," Annali dell'Istituto Superiore di Sanita, vol. 42, no. 1, pp. 4-7, 2006.

[6] D. Dias, M. C. Mendonça, F. C. Real, D. N. Vieira, and H. M. Teixeira, "Suicides in the Centre of Portugal: seven years analysis," Forensic Science International, vol. 234, no. 1, pp. 2228, 2014.
[7] T. M. Wickizer, "State-level estimates of the economic costs of alcohol and drug abuse," Journal of Health Care Finance, vol. 39, no. 3, pp. 71-84, 2013.

[8] G. Scally, "Crunch time for the government on alcohol pricing in England: backtracking on the minimum unit price pledge would be a public health disaster," British Medical Journal, vol. 346, no. 7900, Article ID f1784, 2013.

[9] M. P. Mundt, S. Parthasarathy, F. W. Chi, S. Sterling, and C. I. Campbell, "12-Step participation reduces medical use costs among adolescents with a history of alcohol and other drug treatment," Drug and Alcohol Dependence, vol. 126, no. 1-2, pp. 124-130, 2012.

[10] J. Rehm, C. Mathers, S. Popova, M. Thavorncharoensap, Y. Teerawattananon, and J. Patra, "Global burden of disease and injury and economic cost attributable to alcohol use and alcohol-use disorders," The Lancet, vol. 373, no. 9682, pp. 22232233, 2009.

[11] H. P. Jedema, M. D. Carter, B. P. Dugan, K. Gurnsey, A. S. Olsen, and C. W. Bradberry, "The acute impact of ethanol on cognitive performance in rhesus macaques," Cerebral Cortex, vol. 21, no. 8, pp. 1783-1791, 2011.

[12] A. A.-B. Badawy, C. J. Morgan, J. W. T. Lowett, D. M. Bradley, and R. Thomas, "Decrease in circulating tryptophan availability to the brain after acute ethanol consumption by normal volunteers: implications for alcohol-induced aggressive behaviour and depression," Pharmacopsychiatry, vol. 28, supplement 2, pp. 93-97, 1995.

[13] A. A.-B. Badawy, D. M. Doughrty, D. M. Marsh-Richard, and A. Steptoe, "Activation of liver tryptophan pyrrolase mediates the decrease in tryptophan availability to the brain after acute alcohol consumption by normal subjects," Alcohol and Alcoholism, vol. 44, no. 3, pp. 267-271, 2009.

[14] S. Loeber and T. Duka, "Extinction learning of stimulus reward contingencies: the acute effects of alcohol," Drug and Alcohol Dependence, vol. 102, no. 1-3, pp. 56-62, 2009.

[15] D. M. Dougherty, D. M. Marsh-Richard, E. S. Hatzis, S. O. Nouvion, and C. W. Mathias, "A test of alcohol dose effects on multiple behavioral measures of impulsivity," Drug and Alcohol Dependence, vol. 96, no. 1-2, pp. 111-120, 2008.

[16] H. M. Haughey, L. A. Ray, P. Finan, R. Villanueva, M. Niculescu, and K. E. Hutchison, "Human $\gamma$-aminobutyric acid A receptor $\alpha 2$ gene moderates the acute effects of alcohol and brain mRNA expression," Genes, Brain and Behavior, vol. 7, no. 4, pp. 447454, 2008.

[17] A. Wadleigh and C. F. Valenzuela, "Ethanol increases GABAergic transmission and excitability in cerebellar molecular layer interneurons from GAD67-GFP knock-in mice," Alcohol and Alcoholism, vol. 47, no. 1, pp. 1-8, 2012.

[18] V. Tiwari, P. Veeraiah, V. Subramaniam, and A. B. Patel, "Differential effects of ethanol on regional glutamatergic and GABAergic neurotransmitter pathways in mouse brain," Journal of Neurochemistry, vol. 128, no. 5, pp. 628-640, 2014.

[19] G. Wu, H. Liu, J. Jin et al., "Ethanol attenuates sensory stimulusevoked responses in cerebellar granule cells via activation of $\mathrm{GABA}_{\mathrm{A}}$ receptors in vivo in mice," Neuroscience Letters, vol. 561, pp. 107-111, 2014.

[20] H. L. Halliday, M. M. Reid, and G. McClure, "Results of heavy drinking in pregnancy," British Journal of Obstetrics and Gynaecology, vol. 89, no. 11, pp. 892-895, 1982.

[21] J. R. West and C. A. Blake, "Fetal alcohol syndrome: an assessment of the field," Experimental Biology and Medicine, vol. 230, no. 6, pp. 354-356, 2005. 
[22] R. F. Berman and J. H. Hannigan, "Effects of prenatal alcohol exposure on the hippocampus: spatial behavior, electrophysiology, and neuroanatomy," Hippocampus, vol. 10, no. 1, pp. 94-110, 2000.

[23] D. H. Lindquist, G. Sokoloff, E. Milner, and J. E. Steinmetz, "Neonatal ethanol exposure results in dose-dependent impairments in the acquisition and timing of the conditioned eyeblink response and altered cerebellar interpositus nucleus and hippocampal CA1 unit activity in adult rats," Alcohol, vol. 47, no. 6, pp. 447-457, 2013.

[24] A. Ramezani, I. Goudarzi, T. Lashkarboluki, M. T. Ghorbanian, K. Abrari, and M. E. Salmani, "Role of oxidative stress in ethanol-induced neurotoxicity in the developing cerebellum," Iranian Journal of Basic Medical Sciences, vol. 15, no. 4, pp. 965974, 2012.

[25] J. D. Thomas, E. J. Abou, and H. D. Dominguez, "Prenatal choline supplementation mitigates the adverse effects of prenatal alcohol exposure on development in rats," Neurotoxicology and Teratology, vol. 31, no. 5, pp. 303-311, 2009.

[26] M. Krishnamoorthy, B. A. Gerwe, C. D. Scharer et al., "Low ethanol concentration alters CHRNA5 RNA levels during early human development," Reproductive Toxicology, vol. 30, no. 3, pp. 489-492, 2010.

[27] A. Nardelli, C. Lebel, C. Rasmussen, G. Andrew, and C. Beaulieu, "Extensive deep gray matter volume reductions in children and adolescents with fetal alcohol spectrum disorders," Alcoholism: Clinical and Experimental Research, vol. 35, no. 8, pp. 1404-1417, 2011.

[28] D. Kuehn, S. Aros, F. Cassorla et al., "A prospective cohort study of the prevalence of growth, facial, and central nervous system abnormalities in children with heavy prenatal alcohol exposure," Alcoholism: Clinical and Experimental Research, vol. 36, no. 10, pp. 1811-1819, 2012.

[29] S. F. Tapert, C. Pulido, M. P. Paulus, M. A. Schuckit, and C. Burke, "Level of response to alcohol and brain response during visual working memory," Journal of Studies on Alcohol, vol. 65, no. 6, pp. 692-700, 2004.

[30] D. B. Clark, D. L. Thatcher, and S. F. Tapert, "Alcohol, psychological dysregulation, and adolescent brain development," Alcoholism: Clinical and Experimental Research, vol. 32, no. 3, pp. 375-385, 2008.

[31] S. F. Tapert, G. G. Brown, M. V. Baratta, and S. A. Brown, "fMRI BOLD response to alcohol stimuli in alcohol dependent young women," Addictive Behaviors, vol. 29, no. 1, pp. 33-50, 2004.

[32] S. F. Tapert, A. D. Schweinsburg, V. C. Barlett et al., "Blood oxygen level dependent response and spatial working memory in adolescents with alcohol use disorders," Alcoholism: Clinical and Experimental Research, vol. 28, no. 10, pp. 1577-1586, 2004.

[33] A. M. White, "What happened? Alcohol, memory blackouts, and the brain," Alcohol Research and Health, vol. 27, no. 2, pp. 186-196, 2003.

[34] X. He, E. V. Sullivan, R. K. Stankovic, C. G. Harper, and A. Pfefferbaum, "Interaction of thiamine deficiency and voluntary alcohol consumption disrupts rat corpus callosum ultrastructure," Neuropsychopharmacology, vol. 32, no. 10, pp. 2207-2216, 2007.

[35] S. A. Magrys and M. C. Olmstead, "Alcohol intoxication alters cognitive skills mediated by frontal and temporal brain regions," Brain and Cognition, vol. 85, pp. 271-276, 2014.

[36] C. F. Zorumski, S. Mennerick, and Y. Izumi, "Acute and chronic effects of ethanol on learning-related synaptic plasticity," Alcohol, vol. 48, no. 1, pp. 1-17, 2014.
[37] D. Erritzoe, A. Tziortzi, D. Bargiela et al., "In vivo imaging of cerebral dopamine D3 receptors in alcoholism," Neuropsychopharmacology, vol. 39, no. 7, pp. 1703-1712, 2014.

[38] E. J. Burnett, K. A. Grant, A. T. Davenport, S. E. Hemby, and D. P. Friedman, "The effects of chronic ethanol self-administration on hippocampal $5-\mathrm{HT}_{1 \mathrm{~A}}$ receptors in monkeys," Drug and Alcohol Dependence, vol. 136, pp. 135-142, 2014.

[39] R. P. Vetreno, J. M. Hall, and L. M. Savage, "Alcohol-related amnesia and dementia: animal models have revealed the contributions of different etiological factors on neuropathology, neurochemical dysfunction and cognitive impairment," Neurobiology of Learning and Memory, vol. 96, no. 4, pp. 596-608, 2011.

[40] R. P. Vetreno, R. L. Ramos, S. Anzalone, and L. M. Savage, "Brain and behavioral pathology in an animal model of Wernicke's encephalopathy and Wernicke-Korsakoff syndrome," Brain Research, vol. 1436, pp. 178-192, 2012.

[41] J. Akai and K. Akai, "Neuropathological study of the nucleus basalis of meynert in alcoholic dementia," Arukoru Kenkyuto Yakubutsu Ison, vol. 24, no. 2, pp. 80-88, 1989.

[42] Z. Zhang, Y. Liu, B. Zhou et al., "Altered functional connectivity of the marginal division in Alzheimer's disease," Current Alzheimer Research, vol. 11, no. 2, pp. 145-155, 2014.

[43] B. B. Andersen, "Reduction of Purkinje cell volume in cerebellum of alcoholics," Brain Research, vol. 1007, no. 1-2, pp. 10-18, 2004.

[44] G. Halliday, K. Cullen, and A. Harding, "Neuropathological correlates of memory dysfunction in the Wernicke-Korsakoff syndrome," Alcohol and Alcoholism Supplement, vol. 2, pp. 245251, 1994.

[45] T. Jochum, M. K. Boettger, C. Burkhardt, G. Juckel, and K.-J. Bär, "Increased pain sensitivity in alcohol withdrawal syndrome," European Journal of Pain, vol. 14, no. 7, pp. 713-718, 2010.

[46] M. Mizuguchi, M. Tomonaga, T. Fukusato, and M. Asano, "Acute necrotizing encephalopathy with widespread edematous lesions of symmetrical distribution," Acta Neuropathologica, vol. 78, no. 1, pp. 108-111, 1989.

[47] L. Riethdorf, R. Warzok, and G. Schwesinger, "Alcoholic encephalopathies in autopsy material," Zentralblatt für Pathologie, vol. 137, no. 1, pp. 48-56, 1991.

[48] V. A. Ramchandani, W. F. Bosron, and T. K. Li, "Research advances in ethanol metabolism," Pathologie Biologie, vol. 49, no. 9, pp. 676-682, 2001.

[49] M. D. Levitt, R. Li, E. G. Demaster, M. Elson, J. Furne, and D. G. Levitt, "Use of measurements of ethanol absorption from stomach and intestine to assess human ethanol metabolism," American Journal of Physiology-Gastrointestinal and Liver Physiology, vol. 273, no. 4, pp. G951-G957, 1997.

[50] M. D. Levitt, C. Fine, J. K. Furne, and D. G. Levitt, "Use of maltose hydrolysis measurements to characterize the interaction between the aqueous diffusion barrier and the epithelium in the rat jejunum," The Journal of Clinical Investigation, vol. 97, no. 10, pp. 2308-2315, 1996.

[51] K. S. Pang, "Modeling of intestinal drug absorption: roles of transporters and metabolic enzymes (for the Gillette review series)," Drug Metabolism and Disposition, vol. 31, no. 12, pp. 1507-1519, 2003.

[52] C. M. Oneta, U. A. Simanowski, M. Martinez et al., "First pass metabolism of ethanol is strikingly influenced by the speed of gastric emptying," Gut, vol. 43, no. 5, pp. 612-619, 1998. 
[53] J. Shultz, H. Weiner, and J. Westcott, "Retardation of ethanol absorption by food in the stomach," Journal of Studies on Alcohol, vol. 41, no. 9, pp. 861-870, 1980.

[54] A. J. Sedman, P. K. Wilkinson, E. Sakmar, D. J. Weidler, and J. G. Wagner, "Food effects on absorption and metabolism of alcohol," Journal of Studies on Alcohol, vol. 37, no. 9, pp. 1197$1214,1976$.

[55] S.-L. Lee, G.-Y. Chau, C.-T. Yao, C.-W. Wu, and S.-J. Yin, "Functional assessment of human alcohol dehydrogenase family in ethanol metabolism: significance of first-pass metabolism," Alcoholism: Clinical and Experimental Research, vol. 30, no. 7, pp. 1132-1142, 2006.

[56] Å. Norberg, W. A. Jones, R. G. Hahn, and J. L. Gabrielsson, "Role of variability in explaining ethanol pharmacokinetics: research and forensic applications," Clinical Pharmacokinetics, vol. 42, no. 1, pp. 1-31, 2003.

[57] J. S. Deetz, C. A. Luehr, and B. L. Vallee, "Human liver alcohol dehydrogenase isozymes: reduction of aldehydes and ketones," Biochemistry, vol. 23, no. 26, pp. 6822-6828, 1984.

[58] T. Haseba, Y. Tomita, M. Kurosu, and Y. Ohno, "Dose and time changes in liver alcohol dehydrogenase (ADH) activity during acute alcohol intoxication involve not only class I but also class III ADH and govern elimination rate of blood ethanol," Legal Medicine, vol. 5, no. 4, pp. 202-211, 2003.

[59] T. Haseba, K. Kameyama, K. Mashimo, and Y. Ohno, "Dosedependent change in elimination kinetics of ethanol due to shift of dominant metabolizing enzyme from ADH 1 (Class I) to $\mathrm{ADH} 3$ (Class III) in mouse," International Journal of Hepatology, vol. 2012, Article ID 408190, 8 pages, 2012.

[60] T.-K. Li, S.-J. Yin, D. W. Crabb, S. O'Connor, and V. A. Ramchandani, "Genetic and environmental influences on alcohol metabolism in humans," Alcoholism: Clinical and Experimental Research, vol. 25, no. 1, pp. 136-144, 2001.

[61] T. N. Smolen, A. Smolen, and J. L. van de Kamp, "Developmental profile of hepatic alcohol and aldehyde dehydrogenase activities in long-sleep and short-sleep mice," Alcohol, vol. 7, no. 1, pp. 69-74, 1990.

[62] F. Lundquist, N. Tygstrup, K. Winkler, K. Mellemgaard, and S. Munck-Petersen, "Ethanol metabolism and production of free acetate in the human liver," The Journal of Clinical Investigation, vol. 41, pp. 955-961, 1962.

[63] K. O. Lindros, A. Stowell, P. Pikkarainen, and M. Salaspuro, "Elevated blood acetaldehyde in alcoholics with accelerated ethanol elimination," Pharmacology Biochemistry and Behavior, vol. 13, supplement 1, pp. 119-124, 1980.

[64] J. G. Puig and I. H. Fox, "Ethanol-induced activation of adenine nucleotide turnover. Evidence for a role of acetate," The Journal of Clinical Investigation, vol. 74, no. 3, pp. 936-941, 1984.

[65] T. Sarkola, M. R. Iles, K. Kohlenberg-Mueller, and C. J. P. Eriksson, "Ethanol, acetaldehyde, acetate, and lactate levels after alcohol intake in white men and women: effect of 4-methylpyrazole," Alcoholism: Clinical and Experimental Research, vol. 26, no. 2, pp. 239-245, 2002.

[66] Z. Kayaalti and T. Soylemezoglu, "Distribution of $A D H 1 B$, $A L D H 2, C Y P 2 E 1 * 6$, and CYP2E1 $* 7 \mathrm{~B}$ genotypes in Turkish population," Alcohol, vol. 44, no. 5, pp. 415-423, 2010.

[67] A. J. Montano Loza, M. T. Ramirez Iglesias, I. Perez Diaz et al., "Association of alcohol-metabolizing genes with alcoholism in a Mexican Indian (Otomi) population," Alcohol, vol. 39, no. 2, pp. 73-79, 2006.
[68] J. García-Bañuelos, A. Panduro, D. Gordillo-Bastidas et al., "Genetic polymorphisms of genes coding to alcoholmetabolizing enzymes in Western Mexicans: association of CYP $2 E 1^{*} c 2 / C Y P 2 E 1^{*} 5 B$ allele with cirrhosis and liver function," Alcoholism: Clinical and Experimental Research, vol. 36, no. 3, pp. 425-431, 2012.

[69] K. Y. Seng, L. M. G. Limenta, D. Heng, and E. J. D. Lee, "Population pharmacokinetics and pharmacogenetics of alcohol in Chinese and Indians in Singapore," Journal of Clinical Pharmacy and Therapeutics, vol. 38, no. 2, pp. 141-149, 2013.

[70] Y. Yamada, F. Sun, I. Tsuritani, and R. Honda, "Genetic differences in ethanol metabolizing enzymes and blood pressure in Japanese alcohol consumers," Journal of Human Hypertension, vol. 16, no. 7, pp. 479-486, 2002.

[71] A. Lorenzo, T. Auguet, F. Vidal et al., "Polymorphisms of alcohol-metabolizing enzymes and the risk for alcoholism and alcoholic liver disease in Caucasian Spanish women," Drug and Alcohol Dependence, vol. 84, no. 2, pp. 195-200, 2006.

[72] Y.-C. Chen, G.-S. Peng, M.-F. Wang, T.-P. Tsao, and S.-J. Yin, "Polymorphism of ethanol-metabolism genes and alcoholism: correlation of allelic variations with the pharmacokinetic and pharmacodynamic consequences," Chemico-Biological Interactions, vol. 178, no. 1-3, pp. 2-7, 2009.

[73] M. Laniewska-Dunaj, W. Jelski, K. Orywal, J. Kochanowicz, R. Rutkowski, and M. Szmitkowski, "The activity of class I, II, III and IV of alcohol dehydrogenase (ADH) isoenzymes and aldehyde dehydrogenase (ALDH) in brain cancer," Neurochemical Research, vol. 38, no. 7, pp. 1517-1521, 2013.

[74] R. Sanchez-Alvarez, U. E. Martinez-Outschoorn, Z. Lin et al., "Ethanol exposure induces the cancer-associated fibroblast phenotype and lethal tumor metabolism: implications for breast cancer prevention," Cell Cycle, vol. 12, no. 2, pp. 289-301, 2013.

[75] I. S. Chan, C. D. Guy, M. V. Machado et al., "Alcohol activates the hedgehog pathway and induces related procarcinogenic processes in the alcohol-preferring rat model of hepatocarcinogenesis," Alcoholism: Clinical and Experimental Research, vol. 38, no. 3, pp. 787-800, 2014.

[76] J. M. Cowan Jr., A. Weathermon, J. R. McCutcheon, and R. D. Oliver, "Determination of volume of distribution for ethanol in male and female subjects," Journal of Analytical Toxicology, vol. 20, no. 5, pp. 287-290, 1996.

[77] H. G. E. Endres and O. Grüner, "Comparison of $\mathrm{D}_{2} \mathrm{O}$ and ethanol dilutions in total body water measurements in humans," The Clinical Investigator, vol. 72, no. 11, pp. 830-837, 1994.

[78] A. F. Pizon, C. E. Becker, and D. Bikin, "The clinical significance of variations in ethanol toxicokinetics," Journal of Medical Toxicology, vol. 3, no. 2, pp. 63-72, 2007.

[79] K. E. Maudens, L. Patteet, A. L. N. van Nuijs, C. Van Broekhoven, A. Covaci, and H. Neels, "The influence of the Body Mass Index (BMI) on the volume of distribution of ethanol," Forensic Science International, vol. 243, pp. 74-78, 2014.

[80] M. Marxen, G. Gan, D. Schwarz et al., "Acute effects of alcohol on brain perfusion monitored with arterial spin labeling magnetic resonance imaging in young adults," Journal of Cerebral Blood Flow and Metabolism, vol. 34, no. 3, pp. 472-479, 2014.

[81] L. Burd, J. Blair, and K. Dropps, "Prenatal alcohol exposure, blood alcohol concentrations and alcohol elimination rates for the mother, fetus and newborn," Journal of Perinatology, vol. 32, no. 9, pp. 652-659, 2012.

[82] E. M. Moore and E. P. Riley, "What happens when children with fetal alcohol spectrum disorders become adults?" Current Developmental Disorders Reports, vol. 2, no. 3, pp. 219-227, 2015. 
[83] A. G. Skorput, V. P. Gupta, P. W. Yeh, and H. H. Yeh, "Persistent interneuronopathy in the prefrontal cortex of young adult offspring exposed to ethanol in utero," The Journal of Neuroscience, vol. 35, no. 31, pp. 10977-10988, 2015.

[84] G. Fein and D. J. Meyerhoff, "Ethanol in human brain by magnetic resonance spectroscopy: correlation with blood and breath levels, relaxation, and magnetization transfer," Alcoholism: Clinical and Experimental Research, vol. 24, no. 8, pp. 1227-1235, 2000.

[85] S. M. Zimatkin and A. I. Buben, "Ethanol oxidation in the living brain," Alcohol and Alcoholism, vol. 42, no. 6, pp. 529-532, 2007.

[86] J. Wang, H. Du, X. Ma et al., "Metabolic products of [2$13 \mathrm{C}]$ ethanol in the rat brain after chronic ethanol exposure," Journal of Neurochemistry, vol. 127, no. 3, pp. 353-364, 2013.

[87] S. E. Martínez, J. Vaglenova, J. Sabrià, M. Carmen Martínez, J. Farrés, and X. Parés, "Distribution of alcohol dehydrogenase mRNA in the rat central nervous system. Consequences for brain ethanol and retinoid metabolism," European Journal of Biochemistry, vol. 268, no. 19, pp. 5045-5056, 2001.

[88] D. Galter, A. Carmine, S. Buervenich, G. Duester, and L. Olson, "Distribution of class I, III and IV alcohol dehydrogenase mRNAS in the adult rat, mouse and human brain," European Journal of Biochemistry, vol. 270, no. 6, pp. 1316-1326, 2003.

[89] K. Tokuda, Y. Izumi, and C. F. Zorumski, "Locally-generated acetaldehyde contributes to the effects of ethanol on neurosteroids and LTP in the hippocampus," Neurology and Clinical Neuroscience, vol. 1, no. 4, pp. 138-147, 2013.

[90] E. Borger, L. Aitken, H. Du, W. Zhang, F. J. Gunn-Moore, and S. S. Du Yan, "Is amyloid binding alcohol dehydrogenase a drug target for treating Alzheimer's disease?" Current Alzheimer Research, vol. 10, no. 1, pp. 21-29, 2013.

[91] S. M. Zimatkin, S. P. Pronko, V. Vasiliou, F. J. Gonzalez, and R. A. Deitrich, "Enzymatic mechanisms of ethanol oxidation in the brain," Alcoholism: Clinical and Experimental Research, vol. 30, no. 9, pp. 1500-1505, 2006.

[92] E. Karahanian, M. E. Quintanilla, L. Tampier et al., "Ethanol as a prodrug: brain metabolism of ethanol mediates its reinforcing effects," Alcoholism: Clinical and Experimental Research, vol. 35, no. 4, pp. 606-612, 2011.

[93] D. E. Rhoads, C. Contreras, and S. Fathalla, "Brain levels of catalase remain constant through strain, developmental, and chronic alcohol challenges," Enzyme Research, vol. 2012, Article ID 572939, 6 pages, 2012.

[94] C. M. G. Aragon, F. Rogan, and Z. Amit, "Ethanol metabolism in rat brain homogenates by a catalase- $\mathrm{H}_{2} \mathrm{O}_{2}$ system," Biochemical Pharmacology, vol. 44, no. 1, pp. 93-98, 1992.

[95] C. S. Lieber, "Microsomal ethanol-oxidizing system (MEOS): the first 30 years (1968-1998)-a review," Alcoholism: Clinical and Experimental Research, vol. 23, no. 6, pp. 991-1007, 1999.

[96] Y. Zhong, G. Dong, H. Luo et al., "Induction of brain CYP2E1 by chronic ethanol treatment and related oxidative stress in hippocampus, cerebellum, and brainstem," Toxicology, vol. 302, no. 2-3, pp. 275-284, 2012.

[97] D. R. Koop, "Oxidative and reductive metabolism by cytochrome P450 2E1," The FASEB Journal, vol. 6, no. 2, pp. 724-730, 1992.

[98] T. Leung, R. Rajendran, S. Singh, R. Garva, M. Krstic-Demonacos, and C. Demonacos, "Cytochrome P450 2E1 (CYP2E1) regulates the response to oxidative stress and migration of breast cancer cells," Breast Cancer Research, vol. 15, no. 6, article R107, 2013.
[99] J. Haorah, S. H. Ramirez, N. Floreani, S. Gorantla, B. Morsey, and Y. Persidsky, "Mechanism of alcohol-induced oxidative stress and neuronal injury," Free Radical Biology and Medicine, vol. 45, no. 11, pp. 1542-1550, 2008.

[100] G. A. Deehan Jr., S. R. Hauser, J. A. Wilden, W. A. Truitt, and Z. A. Rodd, "Elucidating the biological basis for the reinforcing actions of alcohol in the mesolimbic dopamine system: the role of active metabolites of alcohol," Frontiers in Behavioral Neuroscience, vol. 7, article 104, 2013.

[101] X.-S. Deng and R. A. Deitrich, "Putative role of brain acetaldehyde in ethanol addiction," Current Drug Abuse Reviews, vol. 1, no. 1, pp. 3-8, 2008.

[102] C. J. Eriksson, "The role of acetaldehyde in the actions of alcohol (update 2000)," Alcoholism Clinical and Experimental Research, vol. 25, no. 5, supplement, pp. 15s-32s, 2001.

[103] A. I. Cederbaum, "Alcohol metabolism," Clinics in Liver Disease, vol. 16, no. 4, pp. 667-685, 2012.

[104] K. Nakamura, K. Iwahashi, A. Furukawa et al., "Acetaldehyde adducts in the brain of alcoholics," Archives of Toxicology, vol. 77, no. 10, pp. 591-593, 2003.

[105] K. Nakamura, K. Iwahashi, M. Itoh et al., "Immunohistochemical study on acetaldehyde adducts in alcohol-fed mice," Alcoholism, Clinical and Experimental Research, vol. 24, no. 4, supplement, pp. 93S-96S, 2000.

[106] G. Xie, K. Krnjević, and J.-H. Ye, "Salsolinol modulation of dopamine neurons," Frontiers in Behavioral Neuroscience, vol. 7, article 52, 2013.

[107] M. E. Quintanilla, M. Rivera-Meza, P. A. Berrios-Cárcamo et al., "Salsolinol, free of isosalsolinol, exerts ethanol-like motivational/sensitization effects leading to increases in ethanol intake," Alcohol, vol. 48, no. 6, pp. 551-559, 2014.

[108] S. Wanpen, P. Govitrapong, S. Shavali, P. Sangchot, and M. Ebadi, "Salsolinol, a dopamine-derived tetrahydroisoquinoline, induces cell death by causing oxidative stress in dopaminergic SH-SY5Y cells, and the said effect is attenuated by metallothionein," Brain Research, vol. 1005, no. 1-2, pp. 67-76, 2004.

[109] A. T. Peana and E. Acquasb, "Behavioral and biochemical evidence of the role of acetaldehyde in the motivational effects of ethanol," Frontiers in Behavioral Neuroscience, vol. 7, article 86, 2013.

[110] M. E. Quintanilla, M. Rivera-Meza, P. Berríos-Cárcamo, B. K. Cassels, M. Herrera-Marschitz, and Y. Israel, "(R)-Salsolinol, a product of ethanol metabolism, stereospecifically induces behavioral sensitization and leads to excessive alcohol intake," Addiction Biology, 2015.

[111] A. Kikonyogo and R. Pietruszko, "Aldehyde dehydrogenase from adult human brain that dehydrogenates $\gamma$-aminobutyraldehyde: purification, characterization, cloning and distribution," Biochemical Journal, vol. 316, part 1, pp. 317-324, 1996.

[112] Y. Zhang and J. Ren, "ALDH2 in alcoholic heart diseases: molecular mechanism and clinical implications," Pharmacology and Therapeutics, vol. 132, no. 1, pp. 86-95, 2011.

[113] J. Bai and Y. Mei, "Overexpression of aldehyde dehydrogenase-2 attenuates neurotoxicity induced by 4 -hydroxynonenal in cultured primary hippocampal neurons," Neurotoxicity Research, vol. 19, no. 3, pp. 412-422, 2011.

[114] S. Manzo-Avalos and A. Saavedra-Molina, "Cellular and mitochondrial effects of alcohol consumption," International Journal of Environmental Research and Public Health, vol. 7, no. 12, pp. 4281-4304, 2010. 
[115] J. Antosiewicz, J. H. Spodnik, M. Teranishi et al., "NADHgenerating substrates reduce peroxyl radical toxicity in RL-34 cells," Folia Morphologica, vol. 68, no. 4, pp. 247-255, 2009.

[116] M. Velayutham, C. Hemann, and J. L. Zweier, "Removal of $\mathrm{H}_{2} \mathrm{O}_{2}$ and generation of superoxide radical: role of cytochrome $\mathrm{c}$ and NADH," Free Radical Biology and Medicine, vol. 51, no. 1, pp. 160-170, 2011.

[117] B. M. Walker and G. F. Koob, “The $\gamma$-aminobutyric acid-B receptor agonist baclofen attenuates responding for ethanol in ethanol-dependent rats," Alcoholism: Clinical and Experimental Research, vol. 31, no. 1, pp. 11-18, 2007.

[118] E. B. Rex, M. L. Rankin, M. A. Ariano, and D. R. Sibley, "Ethanol regulation of $\mathrm{D}_{1}$ dopamine receptor signaling is mediated by protein kinase C in an isozyme-specific manner," Neuropsychopharmacology, vol. 33, no. 12, pp. 2900-2911, 2008.

[119] L. M. Hendrickson, P. Gardner, and A. R. Tapper, "Nicotinic acetylcholine receptors containing the $\alpha 4$ subunit are critical for the nicotine-induced reduction of acute voluntary ethanol consumption," Channels, vol. 5, no. 2, pp. 124-127, 2011.

[120] E. Villegas, R. Estruch, G. Mengod, and R. Cortés, "NMDA receptors in frontal cortex and hippocampus of alcohol consumers," Addiction Biology, vol. 16, no. 1, pp. 163-165, 2011.

[121] M. Correa, M. N. Arizzi, A. Betz, S. Mingote, and J. D. Salamone, "Open field locomotor effects in rats after intraventricular injections of ethanol and the ethanol metabolites acetaldehyde and acetate," Brain Research Bulletin, vol. 62, no. 3, pp. 197-202, 2003.

[122] N. D. Volkow, S. W. Kim, G.-J. Wang et al., "Acute alcohol intoxication decreases glucose metabolism but increases acetate uptake in the human brain," NeuroImage, vol. 64, no. 1, pp. 277283, 2013.

[123] G. U. Corsini, A. Zuddas, U. Bonuccelli, S. Schinelli, and I. J. Kopin, "1-Methyl-4-phenyl-1,2,3,6-tetrahydropyridine (MPTP) neurotoxicity in mice is enhanced by ethanol or acetaldehyde," Life Sciences, vol. 40, no. 9, pp. 827-832, 1987.

[124] L. Heap, R. J. Ward, C. Abiaka et al., "The influence of brain acetaldehyde on oxidative status, dopamine metabolism and visual discrimination task," Biochemical Pharmacology, vol. 50, no. 2, pp. 263-270, 1995.

[125] J. Y. Wan, J. Y. Wang, Y. Wang, and J. Y. Wang, "A comparison between acute exposures to ethanol and acetaldehyde on neurotoxicity, nitric oxide production and NMDA-induced excitotoxicity in primary cultures of cortical neurons," The Chinese Journal of Physiology, vol. 43, no. 3, pp. 131-138, 2000.

[126] F. T. Crews and K. Nixon, "Mechanisms of neurodegeneration and regeneration in alcoholism," Alcohol and Alcoholism, vol. 44, no. 2, pp. 115-127, 2009.

[127] C. Ikonomidou and A. M. Kaindl, "Neuronal death and oxidative stress in the developing brain," Antioxidants and Redox Signaling, vol. 14, no. 8, pp. 1535-1550, 2011.

[128] J. Luo, "Mechanisms of ethanol-induced death of cerebellar granule cells," Cerebellum, vol. 11, no. 1, pp. 145-154, 2012.

[129] S.-Y. Shim and H.-S. Kim, "Oxidative stress and the antioxidant enzyme system in the developing brain," Korean Journal of Pediatrics, vol. 56, no. 3, pp. 107-111, 2013.

[130] A. Augustyniak, K. Michalak, and E. Skrzydlewska, "The action of oxidative stress induced by ethanol on the central nervous system (CNS)," Postępy Higieny i Medycyny Doświadczalnej, vol. 59, pp. 464-471, 2005.

[131] S. K. Reddy, K. Husain, E. C. Schlorff, R. B. Scott, and S. M. Somani, "Dose response of ethanol ingestion on antioxidant defense system in rat brain subcellular fractions," NeuroToxicology, vol. 20, no. 6, pp. 977-987, 1999.

[132] M. Enache, V. Van Waes, E. Vinner, M. Lhermitte, S. Maccari, and M. Darnaudéry, "Impact of an acute exposure to ethanol on the oxidative stress status in the hippocampus of prenatal restraint stress adolescent male rats," Brain Research, vol. 1191, pp. 55-62, 2008.

[133] L. Hipolito, M. J. Sanchez, A. Polache, and L. Granero, "Brain metabolism of ethanol and alcoholism: an update," Current Drug Metabolism, vol. 8, no. 7, pp. 716-727, 2007.

[134] Y. Fukui and H. Sakata-Haga, "Intrauterine environmentgenome interaction and children's development (1): ethanol: a teratogen in developing brain," Journal of Toxicological Sciences, vol. 34, supplement 2, pp. SP273-SP278, 2009.

[135] F. Bosch-Morell, F. Martínez-Soriano, A. Colell, J. C. FernándezCheca, and F. J. Romero, "Chronic ethanol feeding induces cellular antioxidants decrease and oxidative stress in rat peripheral nerves. Effect of $S$-adenosyl-L-methionine and $N$-acetyl-Lcysteine," Free Radical Biology and Medicine, vol. 25, no. 3, pp. 365-368, 1998.

[136] M. Chalimoniuk, S. Jagsz, E. Sadowska-Krepa, S. J. Chrapusta, B. Klapcinska, and J. Langfort, "Diversity of endurance training effects on antioxidant defenses and oxidative damage in different brain regions of adolescent male rats," Journal of Physiology and Pharmacology, vol. 66, no. 4, pp. 539-547, 2015.

[137] K. A. Ansari, D. Bigelow, and E. Kaplan, "Glutathione peroxidase activity in surgical and autopsied human brains," Neurochemical Research, vol. 10, no. 5, pp. 703-711, 1985.

[138] J. Huang and M. A. Philbert, "Distribution of glutathione and glutathione-related enzyme systems in mitochondria and cytosol of cultured cerebellar astrocytes and granule cells," Brain Research, vol. 680, no. 1-2, pp. 16-22, 1995.

[139] R. Dringen and J. Hirrlinger, "Glutathione pathways in the brain," Biological Chemistry, vol. 384, no. 4, pp. 505-516, 2003.

[140] S. M. Somani and K. Husain, "Interaction of exercise training and chronic ethanol ingestion on antioxidant system of rat brain regions," Journal of Applied Toxicology, vol. 17, no. 5, pp. 329-336, 1997.

[141] S. Pizzimenti, E. Ciamporcero, M. Daga et al., "Interaction of aldehydes derived from lipid peroxidation and membrane proteins," Frontiers in Physiology, vol. 4, article 242, 2013.

[142] J. J. Chen, S. Schenker, and G. I. Henderson, “4-Hydroxynonenal levels are enhanced in fetal liver mitochondria by in utero ethanol exposure," Hepatology, vol. 25, no. 1, pp. 142-147, 1997.

[143] V. Ramachandran, A. Perez, J. Chen, D. Senthil, S. Schenker, and G. I. Henderson, "In utero ethanol exposure causes mitochondrial dysfunction, which can result in apoptotic cell death in fetal brain: a potential role for 4-hydroxynonenal," Alcoholism: Clinical and Experimental Research, vol. 25, no. 6, pp. 862-871, 2001.

[144] V. Ramachandran, L. T. Watts, S. K. Maffi, J. Chen, S. Schenker, and G. I. Henderson, "Ethanol-induced oxidative stress precedes mitochondrially mediated apoptotic death of cultured fetal cortical neurons," Journal of Neuroscience Research, vol. 74, no. 4, pp. 577-588, 2003.

[145] S. K. Maffi, M. L. Rathinam, P. P. Cherian et al., "Glutathione content as a potential mediator of the vulnerability of cultured fetal cortical neurons to ethanol-induced apoptosis," Journal of Neuroscience Research, vol. 86, no. 5, pp. 1064-1076, 2008.

[146] A. Rendón-Ramírez, M. Cortés-Couto, A. B. Martínez-Rizo, S. Muñiz-Hernández, and J. B. Velázquez-Fernández, "Oxidative 
damage in young alcohol drinkers: a preliminary study," Alcohol, vol. 47, no. 7, pp. 501-504, 2013.

[147] A. Augustyniak and E. Skrzydlewska, "The influence of Lcarnitine suplementation on the antioxidative abilities of serum and the central nervous system of ethanol-induced rats," Metabolic Brain Disease, vol. 25, no. 4, pp. 381-389, 2010.

[148] W. Liu, M. Kato, A. A. Akhand et al., "4-hydroxynonenal induces a cellular redox status-related activation of the caspase cascade for apoptotic cell death," Journal of Cell Science, vol. 113, no. part 4, pp. 635-641, 2000.

[149] A. Mahr, F. Batteux, S. Tubiana et al., "Brief report: prevalence of antineutrophil cytoplasmic antibodies in infective endocarditis," Arthritis \& Rheumatology, vol. 66, no. 6, pp. 1672-1677, 2014.

[150] H. Raza and A. John, "4-Hydroxynonenal induces mitochondrial oxidative stress, apoptosis and expression of glutathione S-transferase A4-4 and cytochrome P450 2E1 in PC12 cells," Toxicology and Applied Pharmacology, vol. 216, no. 2, pp. 309318, 2006.

[151] K. E. McElhanon, C. Bose, R. Sharma, L. Wu, Y. C. Awasthi, and S. P. Singh, "4 null mouse embryonic fibroblasts exhibit enhanced sensitivity to oxidants: role of 4-hydroxynonenal in oxidant toxicity," Open Journal of Apoptosis, vol. 2, no. 1, pp. 111, 2013.

[152] M. Shimoji, N. Imaizumi, and Y. Aniya, "Modulation of membrane-bound glutathione transferase activity by phospholipids including cardiolipin," Biological and Pharmaceutical Bulletin, vol. 34, no. 2, pp. 209-213, 2011.

[153] K.-H. Moon, N. Tajuddin, J. Brown, E. J. Neafsey, H.-Y. Kim, and M. A. Collins, "Phospholipase A2, oxidative stress, and neurodegeneration in binge ethanol-treated organotypic slice cultures of developing rat brain," Alcoholism: Clinical and Experimental Research, vol. 38, no. 1, pp. 161-169, 2014.

[154] M. A. C. Rodrigues, J. L. Rodrigues, N. M. Martins et al., "Carvedilol protects against cisplatin-induced oxidative stress, redox state unbalance and apoptosis in rat kidney mitochondria," Chemico-Biological Interactions, vol. 189, no. 1-2, pp. 45-51, 2011.

[155] G. Barceló-Coblijn, L. E. Wold, J. Ren, and E. J. Murphy, "Prenatal ethanol exposure increases brain cholesterol content in adult rats," Lipids, vol. 48, no. 11, pp. 1059-1068, 2013.

[156] V. D. Reddy, P. Padmavathi, G. Kavitha, B. Saradamma, and N. Varadacharyulu, "Alcohol-induced oxidative/nitrosative stress alters brain mitochondrial membrane properties," Molecular and Cellular Biochemistry, vol. 375, no. 1-2, pp. 39-47, 2013.

[157] G. Petrosillo, P. Portincasa, I. Grattagliano et al., "Mitochondrial dysfunction in rat with nonalcoholic fatty liver. Involvement of complex I, reactive oxygen species and cardiolipin," Biochimica et Biophysica Acta (BBA)_Bioenergetics, vol. 1767, no. 10, pp. 1260-1267, 2007.

[158] W. Liu, N. A. Porter, C. Schneider, A. R. Brash, and H. Yin, "Formation of 4-hydroxynonenal from cardiolipin oxidation: intramolecular peroxyl radical addition and decomposition," Free Radical Biology and Medicine, vol. 50, no. 1, pp. 166-178, 2011.

[159] E. Rubin and H. Rottenberg, "Ethanol-induced injury and adaptation in biological membranes," Federation Proceedings, vol. 41, no. 8, pp. 2465-2471, 1982.

[160] Y. A. Vladimirov, E. V. Proskurnina, and A. V. Alekseev, "Molecular mechanisms of apoptosis. Structure of cytochrome c-cardiolipin complex," Biochemistry, vol. 78, no. 10, pp. 10861097, 2013.
[161] J. Brown III, N. Achille, E. J. Neafsey, and M. A. Collins, "Binge ethanol-induced neurodegeneration in rat organotypic brain slice cultures: effects of PLA2 inhibitor mepacrine and Docosahexaenoic Acid (DHA)," Neurochemical Research, vol. 34 , no. 2, pp. 260-267, 2009.

[162] M. Akbar, J. Baick, F. Calderon, Z. Wen, and H.-Y. Kim, "Ethanol promotes neuronal apoptosis by inhibiting phosphatidylserine accumulation," Journal of Neuroscience Research, vol. 83, no. 3, pp. 432-440, 2006.

[163] C. R. Horres and Y. A. Hannun, "The roles of neutral sphingomyelinases in neurological pathologies," Neurochemical Research, vol. 37, no. 6, pp. 1137-1149, 2012.

[164] M. Pascual, S. L. Valles, J. Renau-Piqueras, and C. Guerri, "Ceramide pathways modulate ethanol-induced cell death in astrocytes," Journal of Neurochemistry, vol. 87, no. 6, pp. 15351545, 2003.

[165] M. Saito, M. Saito, T. B. Cooper, and C. Vadasz, "Ethanolinduced changes in the content of triglycerides, ceramides, and glucosylceramides in cultured neurons," Alcoholism: Clinical and Experimental Research, vol. 29, no. 8, pp. 1374-1383, 2005.

[166] B. Schatter, S. Jin, K. Löffelholz, and J. Klein, "Cross-talk between phosphatidic acid and ceramide during ethanolinduced apoptosis in astrocytes," BMC Pharmacology, vol. 5, article 3, 2005.

[167] S. Dasgupta, J. A. Adams, and E. L. Hogan, "Maternal alcohol consumption increases sphingosine levels in the brains of progeny mice," Neurochemical Research, vol. 32, no. 12, pp. 22172224, 2007.

[168] M. Saito, G. Chakraborty, R.-F. Mao et al., "Ethanol alters lipid profiles and phosphorylation status of AMP-activated protein kinase in the neonatal mouse brain," Journal of Neurochemistry, vol. 103, no. 3, pp. 1208-1218, 2007.

[169] N. A. Babenko and E. G. Shakhova, "Effects of flavonoids on sphingolipid turnover in the toxin-damaged liver and liver cells," Lipids in Health and Disease, vol. 7, article 1, 2008.

[170] S. A. Novgorodov, T. I. Gudz, and L. M. Obeid, "Long-chain ceramide is a potent inhibitor of the mitochondrial permeability transition pore," The Journal of Biological Chemistry, vol. 283, no. 36, pp. 24707-24717, 2008.

[171] S. M. de La Monte, L. Longato, M. Tong, S. Denucci, and J. R. Wands, "The liver-brain axis of alcohol-mediated neurodegeneration: role of toxic lipids," International Journal of Environmental Research and Public Health, vol. 6, no. 7, pp. 2055-2075, 2009.

[172] M. Saito, G. Chakraborty, M. Hegde et al., "Involvement of ceramide in ethanol-induced apoptotic neurodegeneration in the neonatal mouse brain," Journal of Neurochemistry, vol. 115, no. 1, pp. 168-177, 2010.

[173] G. Wang and E. Bieberich, "Prenatal alcohol exposure triggers ceramide-induced apoptosis in neural crest-derived tissues concurrent with defective cranial development," Cell Death and Disease, vol. 1, no. 5, article e46, 2010.

[174] T.-X. Deng, Z.-X. Wang, X.-Q. Gao et al., "Alcohol-induced proliferation of neurons in mouse hippocampal dentate gyrus: a possible role of ceramide," Sheng Li Xue Bao, vol. 63, no. 6, pp. 479-490, 2011.

[175] T. Ramirez, L. Longato, M. Tong, J. R. Wands, S. M. de la Monte, and M. Dostalek, "Insulin resistance, ceramide accumulation and endoplasmic reticulum stress in experimental chronic alcohol-induced steatohepatitis," Alcohol and Alcoholism, vol. 48, no. 1, pp. 39-52, 2013. 
[176] M. Bae, V. V. R. Bandaru, N. Patel, and N. J. Haughey, “Ceramide metabolism analysis in a model of binge drinking reveals both neuroprotective and toxic effects of ethanol," Journal of Neurochemistry, vol. 131, no. 5, pp. 645-654, 2014.

[177] J. Cerbón and R. D. C. López-Sánchez, "Diacylglycerol generated during sphingomyelin synthesis is involved in protein kinase $\mathrm{C}$ activation and cell proliferation in Madin-Darby canine kidney cells," Biochemical Journal, vol. 373, no. 3, pp. 917924, 2003.

[178] S. A. Novgorodov, D. A. Chudakova, B. W. Wheeler et al., "Developmentally regulated ceramide synthase 6 increases mitochondrial $\mathrm{Ca}^{2+}$ loading capacity and promotes apoptosis," The Journal of Biological Chemistry, vol. 286, no. 6, pp. 46444658, 2011.

[179] Z. Wen and H.-Y. Kim, "Alterations in hippocampal phospholipid profile by prenatal exposure to ethanol," Journal of Neurochemistry, vol. 89, no. 6, pp. 1368-1377, 2004.

[180] F. Gibellini and T. K. Smith, "The Kennedy pathway-de novo synthesis of phosphatidylethanolamine and phosphatidylcholine," IUBMB Life, vol. 62, no. 6, pp. 414-428, 2010.

[181] S. Subbanna, M. Shivakumar, D. Psychoyos, S. Xie, and B. S. Basavarajappa, "Anandamide-CB1 receptor signaling contributes to postnatal ethanol-induced neonatal neurodegeneration, adult synaptic, and memory deficits," The Journal of Neuroscience, vol. 33, no. 15, pp. 6350-6366, 2013.

[182] R. Taléns-Visconti, I. Sanchez-Vera, J. Kostic et al., "Neural differentiation from human embryonic stem cells as a tool to study early brain development and the neuroteratogenic effects of ethanol," Stem Cells and Development, vol. 20, no. 2, pp. 327339, 2011.

[183] J. Suárez, Y. Romero-Zerbo, L. Márquez et al., "Ulcerative colitis impairs the acylethanolamide-based anti-inflammatory system reversal by 5 -aminosalicylic acid and glucocorticoids," PLoS ONE, vol. 7, no. 5, Article ID e37729, 2012.

[184] A. K. Gebeh, J. M. Willets, M. Bari et al., "Elevated anandamide and related $N$-acylethanolamine levels occur in the peripheral blood of women with ectopic pregnancy and are mirrored by changes in peripheral fatty acid amide hydrolase activity," Journal of Clinical Endocrinology and Metabolism, vol. 98, no. 3, pp. 1226-1234, 2013.

[185] K. Tsuboi, Y. Okamoto, N. Ikematsu et al., "Enzymatic formation of $\mathrm{N}$-acylethanolamines from $\mathrm{N}$-acylethanolamine plasmalogen through $\mathrm{N}$-acylphosphatidylethanolaminehydrolyzing phospholipase D-dependent and -independent pathways," Biochimica et Biophysica Acta-Molecular and Cell Biology of Lipids, vol. 1811, no. 10, pp. 565-577, 2011.

[186] N. Maroof, M. C. Pardon, and D. A. Kendall, "Endocannabinoid signalling in Alzheimer's disease," Biochemical Society Transactions, vol. 41, no. 6, pp. 1583-1587, 2013.

[187] P. Garg, R. S. Duncan, S. Kaja, and P. Koulen, "Intracellular mechanisms of $\mathrm{N}$-acylethanolamine-mediated neuroprotection in a rat model of stroke," Neuroscience, vol. 166, no. 1, pp. 252$262,2010$.

[188] G. Lombardi, G. Miglio, F. Varsaldi, A. Minassi, and G. Appendino, "Oxyhomologation of the amide bond potentiates neuroprotective effects of the endolipid $N$-palmitoylethanolamine," Journal of Pharmacology and Experimental Therapeutics, vol. 320, no. 2, pp. 599-606, 2007.

[189] R. S. Duncan, K. D. Chapman, and P. Koulen, "The neuroprotective properties of palmitoylethanolamine against oxidative stress in a neuronal cell line," Molecular Neurodegeneration, vol. 4, no. 1, article 50, 2009.
[190] L. Di Cesare Mannelli, G. D’Agostino, A. Pacini et al., "Palmitoylethanolamide is a disease-modifying agent in peripheral neuropathy: pain relief and neuroprotection share a PPARalpha-mediated mechanism," Mediators of Inflammation, vol. 2013, Article ID 328797, 12 pages, 2013.

[191] R. S. Duncan, H. Xin, D. L. Goad, K. D. Chapman, and P. Koulen, "Protection of neurons in the retinal ganglion cell layer against excitotoxicity by the $\mathrm{N}$-acylethanolamine, $\mathrm{N}$ linoleoylethanolamine," Clinical Ophthalmology, vol. 5, no. 1, pp. 543-548, 2011.

[192] C. Alling, L. Gustavsson, J.-E. Månsson, G. Benthin, and E. Änggård, "Phosphatidylethanol formation in rat organs after ethanol treatment," Biochimica et Biophysica Acta (BBA)Lipids and Lipid Metabolism, vol. 793, no. 1, pp. 119-122, 1984. 


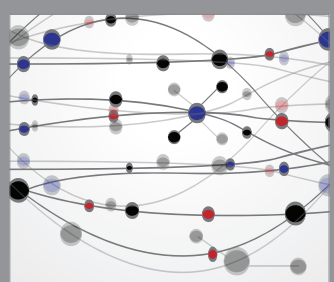

The Scientific World Journal
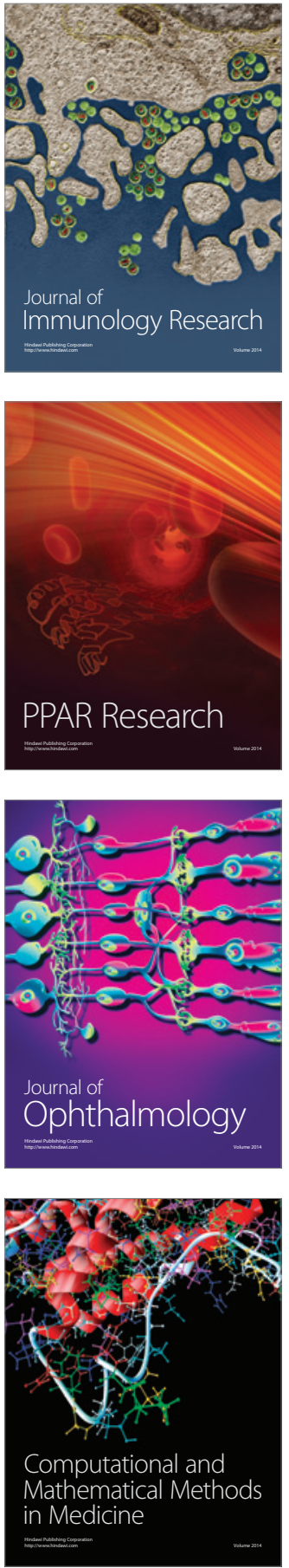

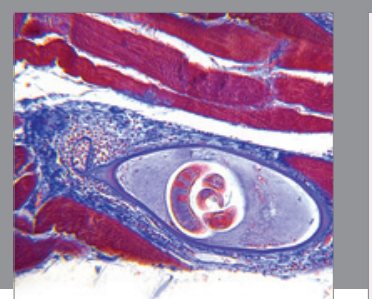

Gastroenterology Research and Practice

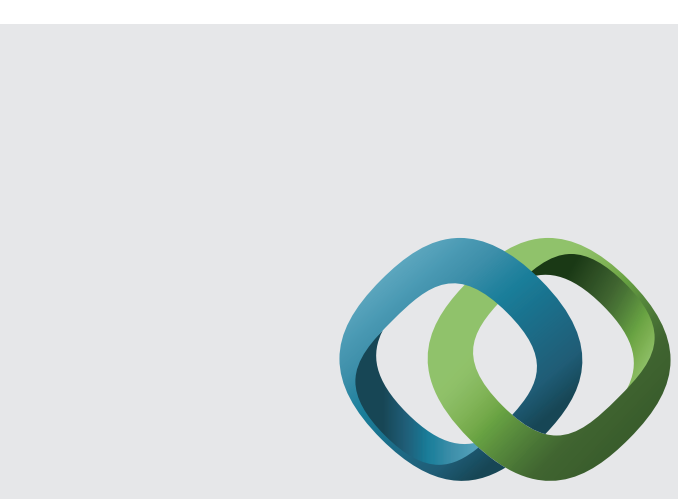

\section{Hindawi}

Submit your manuscripts at

http://www.hindawi.com
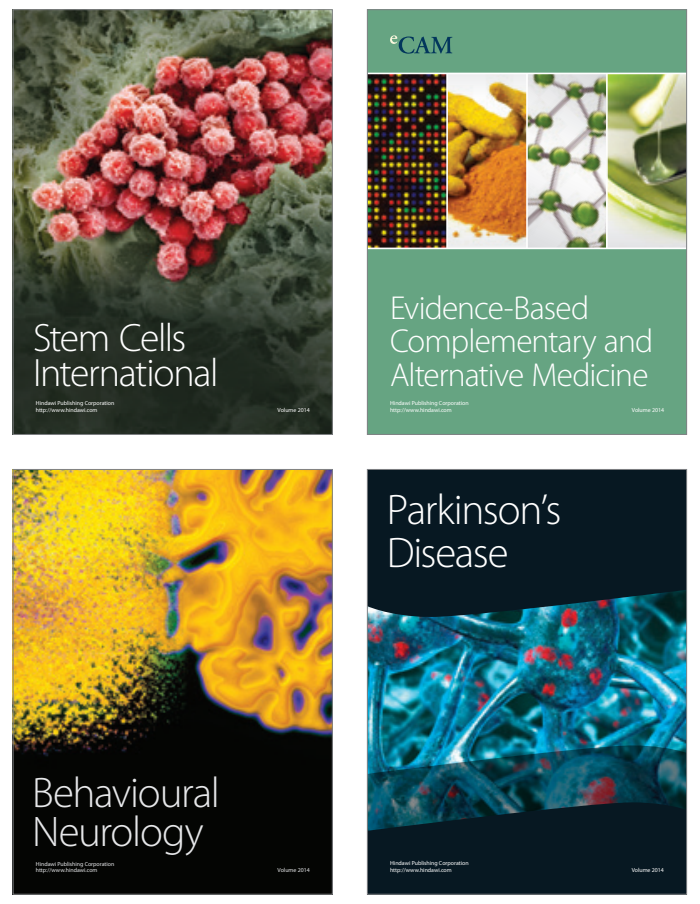
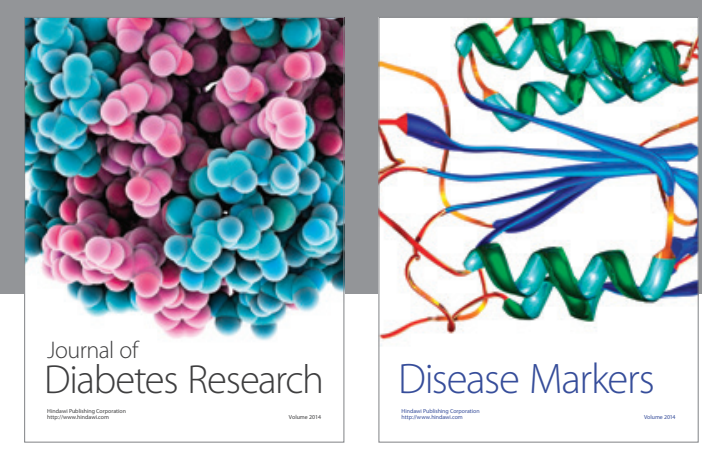

Disease Markers
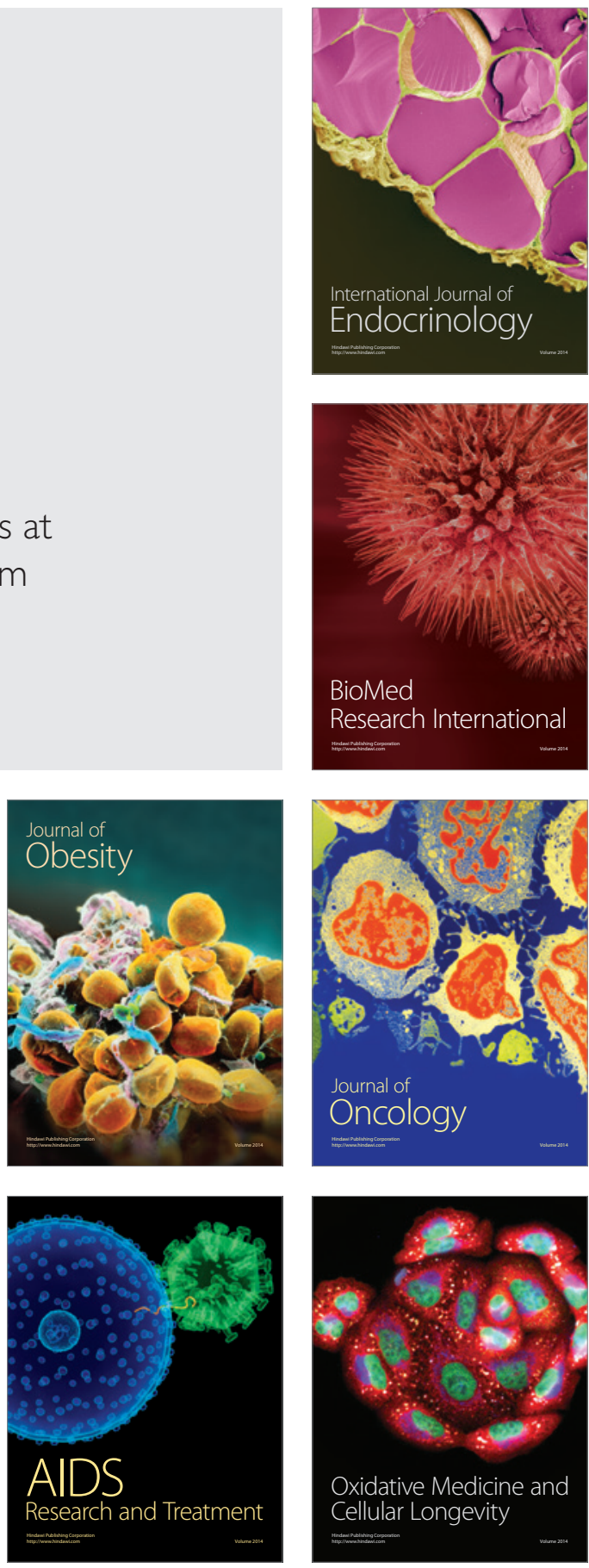